\title{
VOTE BUYING, POLITICAL PATRONAGE AND SELECTIVE PLUNDER*
}

\section{Andrés Cendales ${ }^{* *}$}

This article introduces a political economy model for studying the relationship between the vote-buying strategy of a party that has won the mayoralty of a municipality in the last election and its preferences as the governing party on the municipal political space, given its desire to maintain its position. The main result is that the governing party prefers to promote, given its clientelistic structure, the political agendas with which it selectively impoverishes worse-off (WO) individuals; this will allow that equilibrium prices in vote markets will be reduced in a next election, and therefore, it will help enable the governing party to achieve its objective of maintaining governmental power through its vote-buying strategy in the exchange network.

JEL classification: C72, C70, D31

Keywords: Network games, vote buying, political patronage, poverty, political competition

\section{INTRODUCTION}

This article introduces a model of political economy in order to study the relationship between the vote-buying strategy followed by a party that has won the mayoralty of a municipality in the last election and its preferences over the municipal political space, given its desire to maintain its position in the next election through its vote-buying strategy.

The analysis considers a party system in which, given the existence of informal organizations within the parties, the parties not only do not politically represent the desires and needs of the voters, but they also have a clientelistic structure ${ }^{1}$. As a starting point, we recognize

\footnotetext{
* I would like to thank the referees for their suggestions. I am also grateful for valuable comments from participants at the VI Simposio Nacional de Microeconomia and the XVII Congreso Colombiano de Matemáticas, organized by the Sociedad Colombiana de Matemáticas, as well as those of Felipe Botero, through a book that has taught me about the structures of language games practiced in political science; David Andrade, friend and frank interlocutor, economist and member of the political cabinet of the former mayor of Cali, Jorge Iván Ospina; Federico Vallejo; Krupscaia Sterling (School of Law, Universidad Santiago de Cali); Luciano Brancaccio (Department of Sociology, University of Naples Federico II in Naples, Italy); Oscar Jansson (Department of Anthropology, Uppsala University, Sweden); Manuel Puente (Department of Economics, Universidad de San Andrés, Argentina); Juan Pablo Milanese (Department of Political Science, Universidad Icesi); and Jorge Vallejo Morillo. Finally, I am grateful with all my heart to María Antonia, my beloved mother.

** Graduate Research Assistant, Department of Political Science, Universidad de los Andes, Bogotá, Colombia. Preliminary versions of this document were presented at the Universidad Nacional de Colombia (Bogotá) and the Universidad Externado de Colombia. E-mail: aacendales@gmail.com

1. This implies that the organizational practices of the party are strictly informal, if not invisible, insofar as they are not expressed in the party statutes (Freidenberg and Levitsky 2007: 539).
} 
on the one hand that clientelism has been a prominent characteristic of municipal politics in Colombia (Hoskin 2011: 314, 316), and on the other hand, that "the main criticism directed at contemporary political parties revolves around their representative function, or more specifically, their failure to satisfactorily represent civil society in government agencies" (Hoskin 2011: 295).

In fact, the impact of such a party system on the economy, through the behavior of political institutions and the status quo of the municipal political system-defined as the set of public policies currently being applied in the municipality - is such that it creates a non-prioritarian economy, that is, an economy in which according to the wealth distribution rule, WO persons do not receive any priority with respect to better-off (BO) persons (Vallentyne, 2000; Roemer 2004; Fleurbaey, Tungodden and Vallentyne, 2008; Peragine, 2002; Ruiz-Castillo, 2003; Villar, 2005).

In this context, each voter must decide whether to sell their vote to a political operator in exchange for an up-front payment, to retain it or deliver it to a party at the polls, supporting a government program that will never be implemented. Following the literature on vote buying, a situation in which votes are exchanged for economic payments (not necessarily monetary payments) is a vote market (Dekel, Jackson and Wolinsky, 2008; Schaffer, 2006; Gersbach and Muhe, 2011; Hicken, 2002).

The crucial point is that the payment obtained by the voter in a vote market, regardless of what it is, will always be greater than nothing, which is precisely what the voter obtains with the public policies that are executed, no matter which party is governing. This situation is not implausible, as it occurs in certain Colombian territorial entities such as municipalities, departments or towns where vote buying is a practice widely accepted by voters.

If operators of the governing party, who are in charge of buying the votes of individuals with whom they have ties in an exchange network, have been recruited into the political organization through clientelistic relationships, then the main objective of the proposed analysis is to demonstrate that the governing party will prefer to promote political agendas that selectively impoverish WO individuals through inadequate and inefficient investment of public resources for provision of public goods. Once a political agenda is established thus in the negotiation with other veto players in the municipal political space, equilibrium prices in vote markets will be reduced in the next 
election, and helping the governing party achieve its objective of maintaining governmental power through its vote-buying strategy in the exchange network.

Section 2 presents the bases of the political economy model used to achieve the proposed objective. In that section, I define a sequential game of political competition between two political parties. Each party must decide, given the number of votes bought by the rival party in an earlier stage of the game's history, the quantity of votes it plans to buy in the vote market, which is formally characterized as a network exchange game. In the vote market the voters and the party, through its operators, negotiate the price to be paid for each vote given that they are connected in an exchange network.

What does a party's planned demand for votes in the vote market depend on; what maximizes its payment in the game of political competition? That depends on its equilibrium strategy in the game of political competition. What determines the number of votes that each party operator can actually buy in the vote market, given the party's planned demand? That is determined by equilibrium prices in the vote market and their budget.

Once the election has ended and the winning party becomes the governing party, it must make decisions regarding how to distribute public resources to finance a broad set of public policies based on its political preferences (Volintiru 2010: 10).

Section 3 shows that the governing party's preferences over the political space exhibit the same structure as its preferences over the set of wealth allocation rules $^{2}$. This will support, in the context of rational choice theory, the relationship between the governing party's preferences in the political space and the topology of the exchange network in which it is linked to certain voters through its political operators.

The main result will be established based on the relationship between the subgame perfect Nash equilibrium (SPNE) of the political competition game and the SPNE of each network exchange game that takes place in each stage of the history generated by the equilibrium strategies of the political competition game. Section 4 presents the literature related to vote buying.

2. Public policy literature has not found sufficient information to reject the hypothesis that the set of public policies currently being applied affects the distribution of resources in the economy (Montealegre, 2006: 142; Moser, 2008; Fan, Zhang, and Zhang, 2002; Freidenberg, 2002). 


\section{Preliminaries}

\subsection{Political competition game}

Let $I=\{1,2\}$ be the set of political parties in the political competition game $\Gamma$ such that $\Gamma$ is a sequential game with complete and perfect information. Let $\mathcal{V}=\left\{v_{1}, v_{2}, \ldots, v_{n}\right\}$ be the set of voters and let $A_{i, \tau} \subset\{0,1, \ldots, n\}$ be the set of possible actions available to party $i \in I$ in stage $\tau$ of history $h_{t}=\left(a_{i, \tau}\right)_{\tau=1}^{t}$ such that $a_{i, \tau} \in A_{i, \tau}$ denotes the number of votes bought by party $i$. Let

$$
H_{t}=\times_{\tau=1}^{t} A_{i, \tau}=\left\{\left(a_{i, \tau}\right)_{\tau=1}^{t}: \sum_{\tau=1}^{t}<<n\right\}
$$

be the set of histories of length $t$ of the political competition game ${ }^{3}$. Let $\varepsilon: \mathbb{N} \rightarrow I$ be a function that determines the timing of the game and defined in such a manner that $\varepsilon(\tau)=1$ if $\tau \in 2 \mathbb{N}+1$ and $\varepsilon(\tau)=2$ if $\tau \in 2 \mathbb{N}^{4}$. Note that $\varepsilon(\tau)=\tau$ if $\tau \in I$. Let

$$
\mathbf{a}_{i}\left(h_{t}\right)=a_{i, i}+a_{i, i+2}+a_{i, i+4}+\ldots+a_{i, \tau-2}+a_{i, \tau}
$$

be the number of votes purchased by party $i$ in history $h_{t}$ such that $\tau=t$ if $\varepsilon(\tau)=i$ or $\tau=t=1$ if $\varepsilon(t)=-i$. For each history $h_{t}$ such that $\left|h_{t}\right|>1$, there are histories $h_{s} \in H_{s}$ and $h_{u} \in H_{t-u}$ such that $h_{t}$ results from juxtaposing $h_{s}$ and $h_{u}$; in symbols, $h_{t}=h_{s} \cdot h_{u}$. We note that $\left|h_{t}\right|=\left|h_{s}\right|+\left|h_{u}\right|$.

Possible actions. Let $e_{i, \tau}: A_{i, \tau} \rightarrow \mathbb{R}_{+}$be an increasing function such that $e_{i, \tau}\left(a_{i, \tau}\right)$ is party $i$ 's expenditure if it buys $a_{i, \tau} \in A_{i, \tau}$ votes in stage $\tau$ of history $h_{\tau} \in H_{\tau}$. Let $\mathbf{e}_{i}: \mathbb{Z}_{+} \rightarrow \mathbb{R}_{+}$be a function such that

$$
\mathbf{e}_{i}\left(\mathbf{a}_{i}\left(h_{\tau}\right)\right)=e_{i, i}\left(a_{i, i}\right)+e_{i, i+2}\left(a_{i, i+2}\right)+\ldots+e_{i, \tau}\left(a_{i, \tau}\right)
$$

is the total expenditure of party $i$ if it buys $\mathbf{a}_{i}\left(h_{\tau}\right)$ votes in $h_{\tau}$. The function $\mathbf{e}_{i}$ is increasing given that $\left(e_{i, i}, e_{i, i+2}, \ldots, e_{i, \tau-2}, e_{i, \tau}\right)$ is a sequence of increasing functions. Moreover, $\mathbf{e}_{i}\left(\mathbf{a}_{i}\left(h_{\tau}\right)\right)$ does not depend on $\left|h_{t}\right|$,

3. If $Y$ is a set then $|Y|$ denotes the cardinal of $Y$. We observe that $|\mathcal{V}|=n$. Nevertheless, in regard to a history $h_{t},\left|h_{t}\right|$ will denote the length of $h_{t}$.

4. Party $i$, before blindly deciding on the number of votes to buy, observes the votes that party $-i$ mobilizes during its electoral campaign. The political competition begins with the launch of the parties' electoral campaigns, and never on voting day. 
and hence, if $\sigma, \tau \in \mathbb{Z}_{+}$are positive integers, not necessarily different ones, it holds that $\mathbf{a}_{i}\left(h_{\tau}\right)=\mathbf{a}_{i}\left(h_{\sigma}\right)$ if and only if $\mathbf{e}_{i}\left(\mathbf{a}_{i}\left(h_{\tau}\right)\right)=\mathbf{e}_{i}\left(\mathbf{a}_{i}\left(h_{\sigma}\right)\right) .^{5}$

Following Dekel et al. (2008), the budget $B^{i}$ of party $i$ is exogenous to the model and is obtained by the party from private donations that do not result from control of government resources. Even though the party obtains resources through a combination of state subsidies and private contributions, most financing obtained by the party comes from unregulated private sources. Therefore, as indicated by Freidenberg and Levitsky (2007), investigating the statutes of this type of party will not reveal relevant information about financing obtained in a specific territory. Each party has the capacity to circumvent the state agencies that oversee and limit private campaign financing ${ }^{6}$. In consequence, party $i$ does not know the budget $B^{-i}$ of party $-i$.

On the other hand, party $i$ does not know the function $e_{-i, \tau}$ of party $-i$ in each stage $\tau=\varepsilon^{-1}(-i)$, given that party $i$ does not know the equilibrium prices in the vote markets where $-i$ buys its votes. If $\bar{a}_{i, \tau}=\max A_{i, \tau}$ if and only if $e_{i, \tau}\left(\bar{a}_{i, \tau}\right) \leq B^{i}-\mathbf{e}_{i}\left(\mathbf{a}_{i}\left(h_{\tau-2}\right)\right)<e_{i, \tau}\left(\bar{a}_{i, \tau}+1\right)$ and $a_{1,1}=1$ for any $h_{t}$, then $A_{i, \tau}=\left\{a_{i, \tau}: a_{i, \tau} \leq \bar{a}_{i, \tau}\right\} \subset\{0,1,2, \ldots, n\}$ contains all possible quantities of votes that party $i$ can buy in stage $\tau$ of any history $h_{t} \in H_{t}, i$ where $\bar{a}_{i, \tau}$ is the largest number of votes it can buy.

Payoffs. Party $i$ may only choose action $a_{i, \tau}$ if $\mathbf{a}_{-i}\left(h_{\tau-1}\right) \leq \mathbf{a}_{i}\left(h_{\tau}\right)$, unless its budget proves insufficient, in which case it will buy a number of votes equal to zero, i.e., $a_{i, \tau}=0$; ending the game in stage $\tau$. Following the simple majority criterion, the party that obtains the greatest number of votes wins and gains control of the government budget $W \in \mathbb{R}_{++}$ and its payoff is equal to $v_{-i}\left(h_{t}\right)=W-\mathbf{e}_{-i}\left(\mathbf{a}_{-i}\left(h_{t-1}\right)\right) \in \mathbb{R}_{+}$. Party $i$, as the losing party, obtains a payoff equal to $v_{i}\left(h_{t}\right)=-\mathbf{e}_{i}\left(\mathbf{a}_{i}\left(h_{t}\right)\right) \in \mathbb{R}_{-}$.

Strategies. Even though party $i$ can observe in stage $\tau$ of history $h_{\tau}$ the electoral mass $\mathbf{a}_{-i}\left(h_{\tau-1}\right)$ that party $-i$ has mobilized during its electoral campaign, it does not know the budget $B^{-i}$ of party $-i$ and the exchange network in which party $-i$ buys votes through its operators. In consequence, it does not know $\bar{a}_{i, \tau-1}$; in other words, it does not know the capacity limit of party $-i$. Therefore, party $i$ must

5. This implies that $\mathbf{e}_{i}$, in addition to being a function, is a 1-1 function; injectivity guarantees that if party $i$ incurs two equal expenditures in two different histories, then party $i$ has purchased the same number of votes in each history.

6. In Colombia, this agency is the National Electoral Council (Consejo Nacional Electoral). 
use its best strategy to mobilize its electoral mass in response to the behavior of party $-i$ if it wants to maximize its payoff.

Let $\mathcal{L}_{i}=\left(L_{i, i}, L_{i, i+2}, L_{i, i+4}, \ldots, L_{i, \tau-2}, L_{i, \tau}, \ldots\right)$ be the strategy of party $i$ such that $L_{i, \tau}: H_{\tau-1} \rightarrow A_{i, \tau}$ is a function that assigns to each history $h_{\tau-1} H_{\tau-1}$ a response $a_{i, \tau} \in A_{i, \tau^{*}}$ Note that $\mathbf{a}_{i}\left(h_{\tau}\right) \geq \mathbf{a}_{-i}\left(h_{\tau-1}\right)$ is satisfied for any $\tau$, such that $a_{i, \tau}=0$ if $L_{i, \tau}\left(h_{\tau-1}\right) \notin A_{i, \tau}$. Let us define $H_{0}=\{0\}$ and $L_{1,1}\left(h_{0}\right)=L_{1,1}(0)=1$ for any history $h_{t}$ and any strategic $\mathcal{L}_{i}$.

We say that the set of strategies $\left\{\mathcal{L}_{1}, \mathcal{L}_{2}\right\}$ generates the history $h_{t}=\left(a_{i, \tau}\right)_{\tau=1}^{t}$ if $L_{i, \tau}\left(h_{\tau-1}\right)=a_{i, \tau}$ for any $\tau=1, \ldots t$. Let us denote by $h_{t}=\left\langle\mathcal{L}_{1}, \mathcal{L}_{2}\right\rangle$ the sequence of movements generated by the set of strategies $\left\{\mathcal{L}_{1}, \mathcal{L}_{2}\right\}$, and hence, $\left\langle\mathcal{L}_{1}, \mathcal{L}_{2}\right\rangle=\left(a_{i, \tau}\right)_{\tau=1}^{t}$. In consequence, the notation $v_{i}\left(h_{t}\right)=v_{i}\left(\left\langle\mathcal{L}_{1}, \mathcal{L}_{2}\right\rangle\right)$ acquires full meaning ${ }^{7}$.

How does vote market $\sum[\tau]$, which takes place in stage $\tau$ of history $h_{t}$, operate in political competition game $\Gamma=\left[I,\left\{\mathcal{L}_{1}, \mathcal{L}_{2}\right\},\left\{v_{1}\left(h_{t}\right), v_{2}\left(h_{t}\right)\right\}\right] ?^{8}$

\subsection{Vote market}

Votes are purchased by the party through its operators. Although operators don't possess economic capital, they have social capital that consists not only of knowledge of the community to which they belong, understanding and competently handling the local social habits, but even more importantly, they maintain active connections with a significant number of individuals in the community.

Thus, the party recruits only those individuals who have social capital through which they can gain access to an important number of connections in the community. Because they lack economic capital and resources, the operators are docile instruments who belong exclusively to one party once they become indebted to it over a period of time. This occurs because they enjoy some economic security via a continuous flow of resources, such as bureaucratic positions, special protection and material incentives.

The patron-operator relationship is one of subordination, strictly informal, asymmetric and vertical. While it is true that this relationship exists inside a party with voluntary members, a certain pressure is

7. If at least one player changes its strategy, then the history generated will be different once the sequence of stimuli and responses changes in both parties.

8. Abusing the notation, $\Gamma$ denotes the representation in strategic form of $\Gamma$. 
exercised on the operators, who are coerced in an explicit and direct way $^{9}$ (Rehren 2000: 131; Muno 2010: 4).

Each operator, by using party resources to make certain economic payments to those voters who have agreed to sell their vote, acquires a right over those votes; however, more importantly, those votes become the property of the party. It should be noted that the exchange of votes for economic payments, more than an exchange of favors for services or loyalties, is a purely impersonal exchange. In consequence, each voter knows that beyond the transaction there is no other contractual relationship with the party ${ }^{10}$. Therefore, the patron-operator relationship is not equivalent to the relationship between an operator (vote buyer) and a voter (vote seller) in a vote market.

How can a party operator verify that the votes purchased are effectively acquired at the polling station? Following Schaffer (2006) and Gersbach and Muhe (2011),

(...) there are several strategies for the vote buyers to generate and enforce compliance. For example, vote buyers can instruct voters to fold the ballot in a distinctive way, or to put a pinhole in one corner of the ballot such that vote buyers can easily verify whether the voters have voted as instructed. Another way is to give a voter a fake or stolen pre-marked ballot before entering the polling station. The voter casts the filled-in ballot and gives the official blank ballot to another voter waiting outside. This voter fills out the (received) ballot to the buyer's satisfaction, and goes back into the polling station and repeats the process. Another common practice is to pay voters to abstain from voting, thereby preventing them from casting ballots for the opponent (Gersbach and Muhe 2011: 664).

Now, if a voter agrees to sell their vote given the valuation of that vote, what does its valuation depend on, if the parties do not represent their needs and desires in the context of a non-prioritarian economy,

9. An equilibrium between coercion and compensation enables the patron to establish the clear legitimacy of its political power over its operators, who obey with a certain degree of voluntarism given the acknowledgments and recognition for the debts acquired by him or her. Under these conditions, each patron has the power to set into motion an entire patronage machinery to reach the objectives of the political organization (Freidenberg and Levitsky, 2007).

10. "The director of the Electoral Observation Mission, Alejandra Barrios, stated in a press conference that they determined that in San Onofre, some 584 kilometers northeast of Bogotá, voters requested money, about 100,000 pesos (50 dollars) after voting for candidates of parties such as Apertura Liberal" (La Patria, 2010). 
and therefore the voter does not expect to receive any profit from the political platforms promoted by the parties?

Individual valuations. The demands of a voter in a possible bargaining for his or her vote are low (high) as long as their material living conditions are precarious (favorable), and therefore needs (does not need) to quickly improve their most immediate material situation. In effect, the ethnography shows that WO individuals are willing to sell their votes for low prices given their miserable living conditions, due to which it is impossible for them to obtain the primary goods that it is assumed every individual needs to consume to live in dignified conditions (Betancurth, 2011; Sánchez and Espejo, 2009; El Nuevo Diario, 2010; El Mundo, 2011). Precisely, a voter in the Chocó Department in Colombia states that they sell their vote for just a few pesos, since

(...) we don't even have one peso," said a shocked Julia Susana Mena, a member of the board of directors of the Greater Community Council of the Atrato Integral Peasant Association (Consejo Comunitario Mayor de la Asociación Campesina Integral del Atrato, or ACIA), an umbrella group for traditional authorities from 120 black communities in Medio Atrato, to reporters in the river town of Puerto Conto (Vieira and Cariboni, 2009).

The material living conditions of an individual depend on the income that they produce with their abilities using the resources they possess (wealth). Let $\mathbf{W} \in \mathbb{R}_{+}$be the available wealth in the economy and $w^{\circ} \in \mathbb{R}_{+}$be the minimum wealth required by each individual $v \in \mathcal{V}$ to generate an income. Let $u_{v}:[0, \mathbf{W}] \rightarrow \mathbb{R}_{+}$be a continuous and strictly increasing function such that $u_{v}$ represents the capability of a voter $v \in \mathcal{V}$ such that $u_{v}$ transforms wealth $w$ into the income $u_{v}(w) \in \mathbb{R}_{+}{ }^{11}$.

We assume that $u_{v}\left(w^{\circ}\right)>0$ for any $v \in \mathcal{V}$ such that $u_{v}(w)=0$ if $w<w^{\circ}$. Moreover, we assume that $u_{v}(\mathbf{W})<\infty$ is satisfied for any $v \in \mathcal{V}$ (Moreno-Ternero and Roemer, 2006). Due to a consistency criterion in the difference between the capabilities of two voters, if $u_{v}\left(w^{\circ}\right) \leq u_{v^{\prime}}\left(w^{\circ}\right)$ then $u_{v} \leq u_{v^{\prime}}$. Finally, we assume that $\left(u_{v}\right)_{v \in \mathcal{V}}$ is exogenous ${ }^{12}$.

11. Following García-Pérez and Villar (2009), an individual's capacities depend on certain circumstances for which the voter is not responsible, e.g., the cultural, economic and social background of the voter's family. We assume that voter $v \in \mathcal{V}$ exhibits greater capacities with respect to voter $v^{\prime} \in \mathcal{V}$ if voter $v \in \mathcal{V}$ enjoys more favorable opportunities and circumstances than voter $v^{\prime} \in \mathcal{V}$.

12. It is said that voter $v$ has greater capacity than voter $v^{\prime}$ if and only if $v$ can obtain higher income than the income that $v^{\prime}$ can obtain with the same wealth (Moreno-Ternero and Roemer, 2006). 
Let $u^{\circ}:[0, \mathbf{W}] \rightarrow \mathbb{R}_{+}$be a function such that $u^{\circ}\left(w^{\circ}\right) \in \mathbb{R}_{+}$is an income that enables consumption of a specific set of primary goods such as housing, education, healthcare and access to both public services and the legal system, among others.

Let $\mathcal{V}_{X} \subset \mathcal{V}$ be a social group such that $X \in\{A, B\}$. We say that $v \in \mathcal{V}_{B}$ if and only if $u_{v} \leq u^{\circ}$ and $v \in \mathcal{V}_{A}$ if and only if $u_{v}>u^{\circ}$. Note that $\mathcal{V}_{B} \cap \mathcal{V}_{A}=\emptyset$ and $\mathcal{V}_{A} \cup \mathcal{V}_{B}=\mathcal{V}$ such that $\left\{\mathcal{V}_{A}, \mathcal{V}_{B}\right\}$ is a partition of $\mathcal{V}$. We say that social group $\mathcal{V}_{B}$ contains WO individuals and social group $\mathcal{V}_{A}$ contains BO individuals ${ }^{13}$.

Let $\left(X, x_{i}, \mathbf{x}_{i}\right) \in\left\{\left(B, m_{i}, \mathbf{m}_{i}\right),\left(A, n_{i}, \mathbf{n}_{i}\right)\right\}$ be a triple such that $\mathcal{V}_{X i}$ $=\left\{v_{X i}^{x_{i}}\right\}_{x_{i}=1}^{\mathbf{x}_{i} \in \mathbb{N}} \subset \mathcal{V}_{X}$ denotes the set of voters in social group $\mathcal{V}_{X}$ to whom party $i$ has access through its operators. In consequence, $\mathcal{V}_{i}=\mathcal{V}_{B i} \cup \mathcal{V}_{A i}$ denotes the set of voters who are linked to party $i$. Therefore, $E=\mathcal{V}_{i} \times\{i\}$ is the set of links in a graph $G_{i}=(I \cup \mathcal{V}, E)$ such that $I \cup \mathcal{V}$ is the set of nodes. We say that $G_{i}$ is the exchange network of party $i$.

The restriction established by $G_{i}$ is that voter $v \in \mathcal{V}$ and party $i$ can only exchange votes for economic payments if there is an operator who connects them, given that a party cannot buy votes publicly and openly. The party's need to use its operators' connections arises from the need to carry out vote buying in a silent and invisible way.

The topology of $G_{i}$ describes a situation in which the voters experience the disadvantage of the monopsony, i.e., $\mathcal{V}_{B 1} \cap \mathcal{V}_{B 2}=\emptyset$ and $\mathcal{V}_{A 1} \cap \mathcal{V}_{A 2}=\emptyset$. This is because, on the one hand, an operator manages his or her community connections by using both labor coercion strategies ${ }^{14}$ and territorial coercion strategies ${ }^{15}$; on the other hand, operators do not compete for the vote of a single voter as long as there is a large enough quantity of votes and competition in demand pushes the price of a vote higher. Let $u_{X i}=\left(u_{X i}^{x_{i}}\right)_{x_{i}=1}^{\mathbf{x}_{i} \in \mathbb{N}}$ be the profile of capabilities of the voters who belong to the voter set $\mathcal{V}_{X i}$. Without loss of generality, we assume that $u_{X i}^{x_{i}+1}>u_{X i}^{x_{i}}$ for any $x_{i} \in\left\{1,2, \ldots, \mathbf{x}_{i}-1\right\}$.

13. "In developing countries, the urban poor in particular have little access to and are infrequent users of the legal system. They often live in various forms of illegality -in housing or in work, in the use of electricity - and encounter the legal system primarily in criminal prosecutions" (Desai, 2010: 14).

14. "El Tiempo reported on the case of a leader who has a small factory that provides jobs to 150 female heads of household. One of them said that Escrucería offered the boss 5 million for the votes of all the workers and their families" (Sánchez and Espejo, 2009).

15. "In Bogotá, say candidates for the Council, things have changed a great deal: 'To get into a place you need a leader, who is the neighborhood boss.' Candidates such as Jhon Mario González, a conservative, admit that 'politics is played out at the stoplights' because in some neighborhoods the leaders say they are already backing someone" (Sánchez and Espejo, 2009). 
Given the capabilities of the voters who are linked to party $i$, how is a non-prioritarian economy defined?

Let $F(\mathcal{V})=(F(v))_{v \in \mathcal{V}} \in \mathbb{R}_{+}^{n}$ be an allocation rule for wealth $\mathbf{W}$ such that $F(v) \in \mathbb{R}_{+}$is the voter's wealth $v \in \mathcal{V}$ and $\sum_{v \in \mathcal{V}} F(v) \leq \mathbf{W}$.

Given the capability profile $\left(u_{B i}, u_{A i}\right)$ and the allocation rule $F(\mathcal{V}) \in \mathcal{F}=\left\{F(\mathcal{V}): \sum_{v \in \mathcal{V}} F(v) \leq \mathbf{W}\right\} \subseteq \mathbb{R}_{+}^{n}$ it follows that

$$
\left(\left(u_{B i}^{m_{i}}\left(F\left(v_{B i}^{m_{i}}\right)\right)\right)_{m_{i}=1}^{\mathbf{m}_{i} \in \mathbb{N}},\left(u_{A i}^{n_{i}}\left(F\left(v_{A i}^{n_{i}}\right)\right)\right)_{n_{i}=1}^{\mathbf{n}_{i} \in \mathbb{N}}\right) \in \mathbb{R}_{+}^{\mathbf{m}_{i}+\mathbf{n}_{i}}
$$

is the income vector of voters linked to party $i$ through its operators. We say that $\mathcal{F}$ is the space of wealth allocation rules.

We say that an economy is non-prioritarian if $F(\mathcal{V})$ allocates the lower/higher endowments of wealth to voters who belong to social group $\mathcal{V}_{B} / \mathcal{V}_{A}$. Formally, $F(v)>F\left(v^{\prime}\right)$ if and only if $u_{v}>u_{v^{\prime}}$ for any $v, v^{\prime} \in \mathcal{V}$. In a non-prioritarian economy, the $\mathcal{V}_{B} / \mathcal{V}_{A}$ social group receives the lowest/highest income (Moreno-Ternero and Roemer, 2006; Roemer, 2001; Peragine, 2000, 2002; Ruiz-Castillo, 2003; Villar, 2005).

Let $u_{v}(F(v)) \rightarrow \theta\left(u_{v}(F(v))\right) \in \mathbb{R}_{+}$be a strictly increasing function such that $\theta\left(u_{v}(F(v))\right)=\theta_{v} \in \mathbb{R}_{+}$denotes voter $v \in \mathcal{V}$ 's valuation of his or her vote, which is measured in units of money. We assume not only that $\theta_{v} \in \mathbb{R}_{+}$is common knowledge among the voters and the party operators who are linked in $G_{i}$ but also $\theta_{v}=0$ if $u_{v}(F(v))=0$ for any $v \in \mathcal{V}$ (Blume, Easley, Kleinberg, and Tardos, 2009).

Let $\theta_{X i}=\left(\theta_{X i}^{x_{i}}\right)_{x_{i}=1}^{\mathbf{x}_{i} \in \mathbb{N}} \in \mathbb{R}_{+}^{\mathbf{x}_{i}}$ be the profile of valuations of the set of voters $\mathcal{V}_{X i}$ that is linked to party $i$ in social group $\mathcal{V}_{X}$. Given the existence of a non-prioritarian economy, it holds that $\theta_{X i}^{x_{i}}<\theta_{X i}^{x_{i}+1}$ if $u_{X i}^{x_{i}+1}>u_{X i}^{x_{i}}$ for any $x_{i} \in\left\{1,2, \ldots, \mathbf{x}_{i}-1\right\}^{16}$.

Without loss of generality, we assume that $B^{1}>>B^{2}$ if and only if $A_{2, \tau+1} \subset A_{1, \tau}$ for any $\tau \in \mathbb{N}$. In consequence, $\left|h_{t}\right|$ is even for any strategy profile $\left(\mathcal{L}_{1}, \mathcal{L}_{2}\right)$. Hence, only the uneven stages will be considered with the subsequence $h_{t} \uparrow A_{1}$, which results from eliminating from sequence $h_{t}$ the movements of party 2 . Note that graph $G_{1}$ describes the exchange

16. The formal characterization of the voters' valuations is consistent with the ethnography. A voter in the Department of Chocó (Colombia) says she sells her vote for just a few pesos, as "(...) we don't even have one peso," said Julia Susana Mena, a member of the board of directors of the Greater Community Council of the Atrato Integral Peasant Association (Consejo Comunitario Mayor de la Asociación Campesina Integral del Atrato, or ACIA), which groups together traditional authorities from 120 black communities in Medio Atrato, to shocked reporters in the river town of Puerto Conto (Vieira and Cariboni, 2009). 
network of party 1, which takes place in each of the vote markets in the different stages of history $h_{t} \uparrow A_{1}$. Given exchange network $G_{1}$, how is vote market $\sum[\tau]$, which takes place in $G_{1}$, defined such that $\varepsilon(\tau)=1$ ? $^{17}$

We describe the vote market as a dynamic game $\sum[\tau]$ with complete and perfect information, such that $\tau$ is an uneven stage of $h_{t} \in H_{t}$. The timing of the game $\sum[\tau]$ is as follows: party 1 moves in stage 1 and voter set $\mathcal{V}_{1}$ moves simultaneously in stage $2^{18}$.

Possible actions. Let $\left(\beta_{X 1}^{x_{1}}[\tau]\right)_{x_{i}=1}^{\mathbf{x}_{1} \in \mathbb{N}}=\left(\beta_{X 1}[\tau]\right) \in \mathbb{R}_{+}^{\mathbf{x}_{1}}$ be the bid prices vector of party 1 such that $\beta_{X 1}^{x_{1}}[\tau] \in \mathbb{R}_{+}$is the price the party offers to voter $v_{X 1}^{x_{1}}$ for their vote in the first stage of the game $\sum[\tau]$. Hence, $\beta_{1}[\tau]=\left(\beta_{B 1}[\tau], \beta_{A 1}[\tau]\right) \in \mathbb{R}_{+}^{\mathbf{m}_{1}+\mathbf{n}_{1}}$ is the bids vector that party 1 offers in the first stage of game $\sum[\tau]{ }^{19}$

Each voter $v_{X 1}^{x_{1}}$ may reject $\left(\rho_{X 1}^{x_{1}}[\tau]=0\right)$ or accept $\left(\rho_{X 1}^{x_{1}}[\tau]=1\right)$ the bid price $\beta_{X 1}^{x_{1}}[\tau] \in \mathbb{R}_{+}$in the second stage of game $\sum[\tau]$. Let $\rho_{1}[\tau]=\left(\rho_{B 1}[\tau], \rho_{A 1}[\tau]\right)$ be the vector of voter responses in the second stage of game $\sum[\tau]$ such that $\left(\rho_{X 1}^{x_{1}}[\tau]\right)_{x_{i}=1}^{\mathbf{x}_{1} \in \mathbb{N}}=\rho_{X 1}[\tau] \in\{0,1\}^{\mathbf{x}_{1}}$.

Payoffs. Voter $v_{X 1}^{x_{1}} \in \mathcal{V}_{X 1}$ receives a payoff equal to $\beta_{X 1}^{x_{1}}[\tau]$ if $\rho_{X 1}^{x_{1}}[\tau]=1$; otherwise, he receives a payment equal to $\theta_{X 1}^{x_{1}}$. Given the profile of actions $\left(\beta_{1}[\tau], \rho_{1}[\tau]\right)$, the payoff obtained by party $1^{20}$ is $B^{1}-\beta_{1}[\tau] \cdot\left[\rho_{1}[\tau]\right]^{\top}$.

\section{Results}

Each party $i$ plays in two scenarios: the one in which it competes with party $-i$ for victory in the election, and the one in which it negotiates with voters, through its private operators, the purchase price of each vote. Let us analyze their conduct in each scenario.

Because it is a rational player, if party $i$ wins the election, it will want to do so in such a way as to maximize its payoff. Theorem 1 establishes that party $i$, if it wins the election, maximizes its payment if it buys the smaller number of votes that consumes budget $B^{-i}$ of party $-i$, given the fact that it does not know $B^{-i}$ and exchange network $G_{-i}$.

17. It makes complete sense to state that the exchange of votes for economic payments takes place in an exchange network, in this case, exchange network $G_{1}$.

18. Without loss of generality, the restriction that only those voters who have not sold their vote in a previous stage $h_{\tau}$ can participate is omitted.

19. The vectors are row vectors, such that the transposed $\mathbf{x}^{\top}$ is the column vector of vector $\mathbf{x}$.

20. We assume that party 1 has a sufficiently large budget to buy all the votes in its exchange network. 
Theorem 1. If $B^{i} \gg B^{-i}$ and party $i$ does not know $\bar{a}_{-i, t-2}$, then, given strategy $\mathcal{L}_{-i}$ of party $-i$, party $i$ maximizes its payoff $v_{i}\left(h_{t}\right)$ if and only if $\mathbf{a}_{i}^{*}\left(h_{t-1}\right)=\mathbf{a}_{i}^{*}\left(h_{t-3}\right)+a_{i, t-1}$ such that $a_{i, t-1} \leq \bar{a}_{i, t-2}<L_{-i, t}\left(h_{t-1}\right)$.

Proof. See appendix.

Is there an algorithm with which party $i$ has the possibility of learning element $\bar{a}_{-i, t-2}$, of set $A_{-i, t-1}$, in its interaction with rival party $-i$ in political competition game $\Gamma$ ? Theorem 2 answers this question.

Theorem 2. Let $\mathcal{L}_{i}^{*}=\left(L_{i, \tau}^{*}\right)_{\tau=i}^{\infty}$ be the investigative strategy of party $i$ such that $L_{i, \tau}^{*}\left(h_{\tau-1}\right)=\left[\mathbf{a}_{-i}\left(h_{\tau-1}-\mathbf{a}_{i}\left(h_{\tau-1}\right)\right]+1\right.$ if $L_{i, \tau}^{*}\left(h_{\tau-1}\right) \in A_{i, \tau}$ and $L_{i, \tau}^{*}\left(h_{\tau-1}\right)=0$ otherwise. We assume that $L_{1,1}^{*}\left(h_{0}\right)=1$. The investigative strategy $\mathcal{L}_{i}^{*}$ is weakly dominant ${ }^{21}$.

Proof. See appendix.

Let $h_{t}=\left(1, a_{2,2}, \ldots, a_{1, t-1}, a_{2, t}\right) \in H_{t}$ be a history of game $\Gamma$. For each action $a_{i, \tau} \in A_{i, \tau}$ such that $\tau<t$, there are histories $h_{v}=\left(1, a_{2,2}, \ldots, a_{i, \tau-1}\right)$ and $h_{w}=\left(a_{i, \tau}, \ldots, a_{1, t-1}, a_{2, t}\right)$ such that $h_{t}=h_{v} . h_{w}$. Let $\Gamma\left[a_{i, \tau}\right]$ be a sub-game of $\Gamma$ such that $\tau<t$ and $H_{t}\left[a_{i, \tau}\right]=\left\{a_{i, \tau}\right\} \times A_{-i, \tau+1} \times \ldots \times A_{1, t-1} \times A_{2, t}$ is the set of histories. It is clear that $h_{w} \in H_{t}\left[a_{i, \tau}\right]$ is a history of subgame $\Gamma\left[a_{i, \tau}\right]$ and $h_{v} . h_{z} \in H_{t}$ for any $h_{z} \in H_{t}\left[a_{i, \tau}\right]$. By Theorem 2, it is not difficult to see that $\mathcal{L}_{i}^{*}$ is weakly dominant in subgame $\Gamma\left[a_{i, \tau}\right]$. In particular, $v_{i}\left(\left\langle\mathcal{L}_{i}^{*}, \mathcal{L}_{-i}^{*}\right\rangle\right) \geq v_{i}\left(\left\langle\mathcal{L}_{i}, \mathcal{L}_{-i}^{*}\right\rangle\right)$ for any $\mathcal{L}_{i} \neq \mathcal{L}_{i}^{*}$ in sub-game $\Gamma\left[a_{i, \tau}\right]$, i.e., $\left(\mathcal{L}_{1}^{*}, \mathcal{L}_{2}^{*}\right)$ induces a Nash equilibrium in each subgame. Thus, $\left(\mathcal{L}_{1}^{*}, \mathcal{L}_{2}^{*}\right)$ is an SPNE in game $\Gamma$.

Corollary 3. Strategy profile $\left(\mathcal{L}_{1}^{*}, \mathcal{L}_{2}^{*}\right)$ is an SPNE of game $\Gamma$.

Note that in history $h_{t}^{*}=\left\langle\mathcal{L}_{1}^{*}, \mathcal{L}_{2}^{*}\right\rangle$ it holds that $a_{1,1}=1$ and $a_{1, \tau}=2$ for all $\tau=2, \ldots, t-1$ such that $\mathbf{a}_{2}\left(h_{t}^{*}\right)=t-2$ and 
$v_{1}\left(h_{t}^{*}\right)=W-\mathbf{e}_{1}(t-1)^{22}$. In particular, to determine the value of expenditure $\mathbf{e}_{1}(t-1)$ it is necessary to find the SPNE of each vote market $\sum[\tau]$ that has taken place in each stage $\tau$ of history $h_{t}^{*} \uparrow A_{1}$.

Given that $\sum[\tau]$ is a dynamic game with only two stages, in the first stage party 1 moves and in the second stage the set of voters $\mathcal{V}_{1}$ moves simultaneously. Let $\mathbf{y}_{0}$ be the initial node of game $\sum[\tau]$ and let $H_{1}\left(\mathbf{y}_{0}\right)$ be the set of information of party 1 such that $\mathbf{C}\left(H_{1}\left(\mathbf{y}_{0}\right)\right)=\mathbb{R}_{+}^{\mathbf{m}_{1}+\mathbf{n}_{1}}$ is its set of available actions and $\beta_{1}[\tau] \in \mathbb{R}_{+}^{\mathbf{m}_{1}+\mathbf{n}_{1}}$ is an action of the set $\mathbf{C}\left(H_{1}\left(\mathbf{y}_{0}\right)\right)$.

Let $H_{X 1}^{x_{1}}\left(\mathbf{y}_{X 1}^{x_{1}}\right) \rightarrow \xi_{X 1}^{x_{1}}\left(H_{X 1}^{x_{1}}\left(\mathbf{y}_{X 1}^{x_{1}}\right)\right)=\rho_{X 1}^{x_{1}}[\tau] \in\{0.1\}$ be a pure strategy of voter $v_{X 1}^{x_{1}}$ such that $\mathbf{y}_{X 1}^{x_{1}}$ is the immediate successor of node $\mathbf{y}_{0}$ in the tree of game $\sum[\tau]$ and $H_{X 1}^{x_{1}}\left(\mathbf{y}_{X 1}^{x_{1}}\right)$ is its set of information. Therefore, $\mathbf{C}\left(H_{X 1}^{x_{1}}\left(\mathbf{y}_{X 1}^{x_{1}}\right)\right)=\{0.1\}$ is the set of actions available to voter $v_{X 1}^{x_{1}}$ at node $\mathbf{y}_{X 1}^{x_{1}}$.

If voter $v_{X 1}^{x_{1}}$ is rational, then $\xi_{X 1}^{x_{1}}$ is their optimal strategy if $\xi_{X 1}^{x_{1}}$ is defined as follows: $\xi_{X 1}^{x_{1}}\left(H_{X 1}^{x_{1}}\left(\mathbf{y}_{X 1}^{x_{1}}\right)\right)=1$ if $\beta_{X 1}^{x_{1}}[\tau] \geq \theta_{X 1}^{x_{1}}$ and $\xi_{X 1}^{x_{1}}\left(H_{X 1}^{x_{1}}\left(\mathbf{y}_{X 1}^{x_{1}}\right)\right)=0$ if $\beta_{X 1}^{x_{1}}[\tau]<\theta_{X 1}^{x_{1}}$. If party 1 considers the optimal strategy profile $\xi_{1}=\left(\xi_{B 1}, \xi_{A 1}\right)$ in the first stage of game $\sum[\tau]$ such that $\xi_{X 1}=\left(\xi_{X 1}^{x_{1}}\left(H_{X 1}^{x_{1}}\left(\mathbf{y}_{X 1}^{x_{1}}\right)\right)\right)_{x_{1}=1}^{\mathbf{x}_{1}}$, then, $B^{1}-\beta_{1}[\tau] \cdot \xi_{1}^{\top}$ is its objective function, such that $\beta_{1}[\tau] \in \mathbb{R}_{+}^{\mathbf{m}_{1}+\mathbf{n}_{1}}$ is its decision variable.

Hence, $H_{1}\left(\mathbf{y}_{0}\right) \rightarrow \xi_{2}\left(H_{1}\left(\mathbf{y}_{0}\right)\right)=\left(\beta_{B 1}[\tau], \beta_{A 1}[\tau]\right)$ is the optimal strategy of party 1 if $\beta_{A 1}[\tau]<\theta_{A 1},\left(\beta_{B 1}^{m_{1}}[\tau]\right)_{m_{1}=3}^{\mathbf{m}_{1}}<\left(\theta_{B 1}^{m_{1}}\right)_{m_{1}=3}^{\mathbf{m}_{1}}$ and $\beta_{B 1}^{m_{1}}[\tau]=\theta_{B 1}^{m_{1}}$ for $m_{1}=1,2$. In effect, if $\xi_{2}\left(H_{1}\left(\mathbf{y}_{0}\right) \cdot \rho_{1}^{\top}[\tau]=\theta_{B 1}^{1}+\theta_{B 1}^{2}\right.$, then, $\theta_{B 1}^{1}+\theta_{B 1}^{2}<\beta_{1}[\tau] . \xi_{1}^{\top}$ for any $\beta_{1}[\tau] \in \mathbb{R}_{+}^{\mathbf{m}_{1}+\mathbf{n}_{1}}$ if $\theta_{B 1}^{m_{1}}<\theta_{B 1}^{m_{1}+1}$ for all $m_{1}=1,2, \ldots, \mathbf{m}_{1}-1$. Given that the only subgame of $\sum[\tau]$ is the game $\sum[\tau]$, the following theorem has been demonstrated.

Theorem 4. Strategy profile $\left(\xi_{1}, \xi_{2}\right)$ is an SPNE of game $\sum[\tau]$.

Note that given the structure of exchange network $G_{1}$, expenditure $\mathbf{e}_{1}(t-1)$ is equal to the sum of the valuations of WO individuals who live in the worst conditions in exchange network $G_{1}$.

22. It has been observed that situations in which the difference between electoral quotas reached by the parties is quite small in the context of vote buying are quite common (Barco and Jaramillo 2005; La Patria 2010; Revista Gobierno, 2011). 
Corollary 5. If $\left(\mathcal{L}_{1}^{*}, \mathcal{L}_{2}^{*}\right)$ is an SPNE of game $\Gamma$ such that $h_{t}^{*}=\left(\left\langle\mathcal{L}_{1}^{*}, \mathcal{L}_{2}^{*}\right\rangle\right)$ and $\left(\xi_{1}, \xi_{2}\right)$ is an SPNE of game $\sum[\tau]$ such that $\varepsilon(\tau)=1$, then, party 1 wins the political competition by buying the votes of the poorest voters with which it is linked in exchange network $G_{1}$, i.e., $\mathbf{e}_{1}(t-1)=\sum_{m_{1}=1}^{t-1} \theta_{B 1}^{m_{1}}$.

Which political agenda will party 1 promote as a governing party, in the political space, given its goal of maintaining power by buying votes?

\subsection{Main result}

The political space. The creation of public policies is the main result of a political system, and political actors are precisely those who propose the different public policy measures that affect the distribution of resources in the economy.

Assuming that the wealth of individuals who belong to political organizations and government agencies is not accounted for in $\mathbf{W} \in \mathbb{R}_{+}$, let $\Phi: \mathcal{F} \rightarrow \mathbb{R}_{+}^{2}$ be a vector field such that $\Phi(F(\mathcal{V}))=\left(\mathbf{W}_{B}, \mathbf{W}_{A}\right)=\left(\sum_{v \in \mathcal{V}_{B}} F(v), \sum_{v \in \mathcal{V}_{A}} F(v)\right)$. Therefore, given wealth allocation rule $F(\mathcal{V})$, each point $\left(\mathbf{W}_{B}, \mathbf{W}_{A}\right)$ specifies the way in which wealth $\mathbf{W}$ is distributed among social groups $\mathcal{V}_{A}$ and $\mathcal{V}_{B}$. Let $\Phi(\mathcal{F})=\left\{\left(\mathbf{W}_{B}, \mathbf{W}_{A}\right): \mathbf{W}_{B}+\mathbf{W}_{A} \leq \mathbf{W}\right\} \subset \mathbb{R}_{+}^{2}$ be the image of the set $\mathcal{F} \subset \mathbb{R}_{+}^{n}$ through $\Phi$.

Note that $\Phi$ is not 1-1; while it is true that for each wealth allocation rule $F(\mathcal{V}) \in \mathcal{F}$ there is one and only one allocation rule $\left(\mathbf{W}_{B}, \mathbf{W}_{A}\right) \in \mathbb{R}_{+}^{2}$, for each allocation rule $\left(\mathbf{W}_{B}, \mathbf{W}_{A}\right) \in \mathbb{R}_{+}^{2}$ there can be different allocation rules $F(\mathcal{V})$ and $F^{\prime}(\mathcal{V})$ such that $\mathbf{W}_{B}=\sum_{v \in \mathcal{V}_{B}} F(v)=\sum_{v \in \mathcal{V}_{B}} F^{\prime}(v)$ and $\mathbf{W}_{A}=\sum_{v \in \mathcal{V}_{A}} F(v)=\sum_{v \in \mathcal{V}_{A}} F^{\prime}(v)$. Hence, at the intergroup level, allocation rule $F(\mathcal{V})$ can allocate wealth in a different way than allocation rule $F^{\prime}(\mathcal{V})$, even if at the intergroup level their shares are equal.

Let $\mathbf{P}$ be a set of public policies such that $\mathcal{P}=2^{\mathbf{P}}-\{\emptyset\}$ is the political space and $2^{\mathbf{P}}$ is the power set of $\mathbf{P}$. Note that set $\mathcal{P}$ provides a more adequate characterization of the political space with respect to set $\mathbf{P}$ if the political agenda established in the political system involves the execution of a set of public polices rather than a single public policy.

Let $\psi: \mathcal{P} \rightarrow \Phi(\mathcal{F}) \subset \mathbb{R}_{+}^{2}$ be a function such that $\mathbf{x}=\psi(\sigma) \in \Phi(\mathcal{F})$ is a wealth allocation rule $\mathbf{W}$ among social groups $\mathcal{V}_{A}$ and $\mathcal{V}_{B}$ given the set of public policies $\sigma \in \mathcal{P}$ that has been implemented in the economy. We say that $\sigma \in \mathcal{P}$ is a political agenda. 
Given that the target populations of a political agenda are social groups $\mathcal{V}_{A}$ and $\mathcal{V}_{B}$ rather than isolated individuals, it is assumed that for each wealth allocation rule $\left(\mathbf{W}_{B}, \mathbf{W}_{A}\right) \in \Phi(\mathcal{F})$ there is one and only one political agenda $\sigma \in \mathcal{P}$ such that $\left(\mathbf{W}_{B}, \mathbf{W}_{A}\right)=\psi(\sigma)$, i.e., $\psi$ is a bijective function. In other words, we are saying not only that $\mathcal{P}$ and $\Phi(\mathcal{F})$ are equipotent, but also that for each allocation rule $\left(\mathbf{W}_{B}, \mathbf{W}_{A}\right)$ among social groups $\mathcal{V}_{A}$ and $\mathcal{V}_{B}$ there is one and only one political agenda $\sigma$ that induces it.

Figure 1. Political agenda and allocation rule

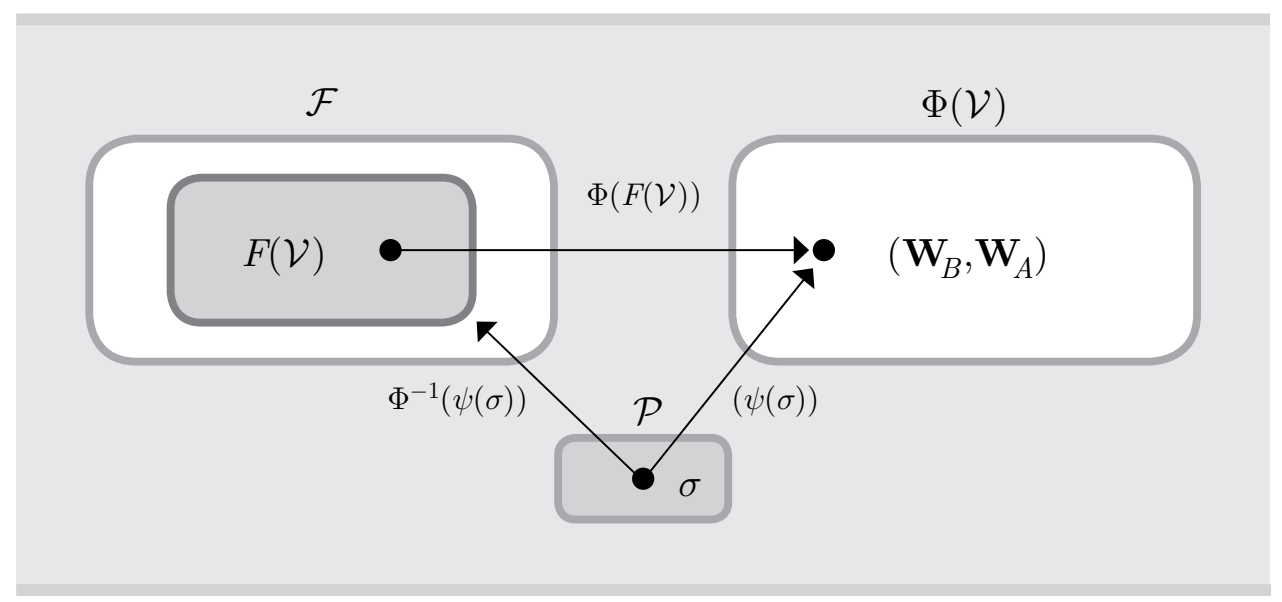

The diagram described shows how the political agenda is a necessary condition, but not a sufficient one, to determine the choice of a certain allocation rule.

Because $\Phi$ is not 1-1, it can be observed that for each political agenda $\sigma$ there is a corresponding set of wealth allocation rules $\Phi^{-1}\left(\mathbf{W}_{B}, \mathbf{W}_{A}\right)=\Phi^{-1}(\psi(\sigma)) \subset \mathcal{F}$ such that $\Phi^{-1}\left(\mathbf{W}_{B}, \mathbf{W}_{A}\right)$ is the preimage of $\left(\mathbf{W}_{B}, \mathbf{W}_{A}\right)$ for $\Phi$. While I do make a theoretical assumption that a political agenda $\sigma$ has an impact on wealth distribution $\mathbf{W}$ among social groups $\mathcal{V}_{A}$ and $\mathcal{V}_{B}$ through the provision of infrastructure, public services and security, among others, allocation rule $F(\mathcal{V}) \in \Phi^{-1}(\psi(\sigma))$ that takes place in the economy will depend not only on political agenda $\sigma$ established in the municipal political system but also on the economic activity of each individual in the public and/or private sector.

We say that the status quo of the political system is the political agenda $\sigma^{*} \in \mathcal{P}$ that is currently applied in the municipal economy. Let $\mathbf{s q}=\psi\left(\sigma^{*}\right) \in \Phi(\mathcal{F})$ such that $\mathbf{s q}=\left(\mathbf{W}_{B}^{*}, \mathbf{W}_{A}^{*}\right) \in\left[e_{2} \mathbf{W},(\mathbf{W} / 2)\left(e_{1}+e_{2}\right)\right]$ 
because the municipal economy is non-prioritarian ${ }^{23}$. Given that $\psi$ is a bijection, we say that sq is the status quo of the municipal political system and $\Phi(\mathcal{F}) \subset \mathbb{R}_{+}^{2}$ is the political space.

Governing party preferences. All political actors are rational in the sense of rational choice theory, i.e., they seek to maximize the realization of their system of objectives with the choice of certain actions in the political space. These actions are restricted by the institutions of a political system. We assume that mayor or governing party (A) has direct preferences on political space $\mathcal{P}$.

Let $\gtrsim_{\mathrm{A}}: \mathcal{P} \rightarrow \mathcal{P}$ be a binary relationship on the political space $\mathcal{P}$ such that $\gtrsim_{\mathbf{A}}$ is reflexive, transitive and complete. We read $\sigma \gtrsim_{\mathbf{A}} \sigma^{\prime}$ as " $\sigma$ is weakly preferred to $\sigma^{\prime \prime}$. Let $\sigma_{\mathbf{A}} \in \mathcal{P}$ be the political agenda that A presumes to be optimal, given its scheme of objectives; hence, $\sigma_{\mathbf{A}} \gtrsim_{\mathbf{A}} \sigma$ for all $\sigma \in \mathcal{P}$. We say that $\mathbf{x}_{\mathbf{A}}=\psi\left(\sigma_{\mathbf{A}}\right)$ is A's ideal point.

Let $\succsim_{\mathbf{A}}: \Phi(\mathcal{F}) \rightarrow \Phi(\mathcal{F})$ be a binary relation on $\Phi(\mathcal{F})$ such that

$$
\left(\mathbf{W}_{B}, \mathbf{W}_{A}\right) \succsim_{\mathbf{A}}\left(\mathbf{W}_{B}^{\prime}, \mathbf{W}_{A}^{\prime}\right) \Leftrightarrow \psi^{-1}\left(\left(\mathbf{W}_{B}, \mathbf{W}_{A}\right) \succsim_{\mathbf{A}} \psi^{-1}\left(\left(\mathbf{W}_{B}^{\prime}, \mathbf{W}_{A}^{\prime}\right)\right)\right.
$$

The relation $\succsim_{\mathbf{A}}$ is well defined given that $\psi$ is a bijection. In words, if $\left(\mathbf{W}_{B}, \mathbf{W}_{A}\right)$ is weakly preferred to $\left(\mathbf{W}_{B}^{\prime}, \mathbf{W}_{A}^{\prime}\right)$, then $\sigma=\psi^{-1}\left(e_{1} \mathbf{W}_{B}+e_{2} \mathbf{W}_{A}\right)$ is weakly preferred to $\sigma^{\prime}=\psi^{-1}\left(e_{1} \mathbf{W}_{B}^{\prime}+e_{2} \mathbf{W}_{A}^{\prime}\right)$, and vice versa.

What is the geometric location of ideal point $\mathbf{x}_{\mathbf{A}}$ of $\mathrm{A}$ in political space $\Phi(\mathcal{F})$ ? To answer this question we will use the following method. Given allocation rule $F^{*}(\mathcal{V}) \in \mathbb{R}_{+}^{n}$ which induces allocation $\left(\mathbf{W}_{B}, \mathbf{W}_{A}\right)=\Phi\left(F^{*}(\mathcal{V})\right)$ among social groups $\mathcal{V}_{A}$ and $\mathcal{V}_{B}$ such that $\left(\mathbf{W}_{B}, \mathbf{W}_{A}\right)=\psi\left(\sigma^{*}\right)$, and given expenditure $\mathbf{e}_{1}(t-1)$, which depends on the topology of exchange network $G_{1}$, first we will study the set of wealth allocation rules that A strictly prefers to $F^{*}(\mathcal{V})$, given their goal of incurring the lowest expense in buying votes in the following election.

Second, given the set of allocation rules strictly prefered to $F^{*}(\mathcal{V})$, through $\Phi$ we will find the set of points in $\Phi(\mathcal{F})$ that are strictly preferred to the status quo sq $=\psi\left(\sigma^{*}\right)$. Clearly, given bijection $\psi: \mathcal{P} \rightarrow \Phi(\mathcal{F})$, the latter enables the inference of something about the set of political

23. Vectors $e_{1}$ and $e_{2}$ are the vectors of the canonic basis. Also, if $\mathbf{a}$ and $\mathbf{b}$ are points of $\mathbb{R}^{2}$, then it is said that $[\mathbf{a}, \mathbf{b}]=\{\mathbf{x}=t \mathbf{a}+(1-t) \mathbf{b}: 0 \leq t \leq 1\}$ is a segment; in this case, a closed segment. Analogously, an open and semi-open segment is defined in $\mathbb{R}^{2}$. 
agendas that the governing party strictly prefers to the status quo $\sigma^{*}$, and which therefore it will want to promote in political space $\mathcal{P}$.

Let $M I\left[F^{*}(\mathcal{V})\right] \subset \mathcal{F}$ be a set of allocation rules such that $\left[F_{\lambda}(\mathcal{V})\right] \in M I\left[F^{*}(\mathcal{V})\right]$ if and only if $F_{\lambda}(v)=F^{*}(v)-\lambda$ for all $v \in\left\{v_{B 1}^{m_{1}}\right\}_{m_{1}=1}^{t-1}$ such that $\lambda \in\left[0, \mathbf{w}_{1}\right]=\left[0, F^{*}\left(v_{B 1}^{1}\right)\right]$, and $F_{\lambda}(v)=F^{*}(v)$ for any $v \in \mathcal{V}-\left\{v_{B 1}^{m_{1}}\right\}_{m_{1}=1}^{t-1}$. We assume that $F^{*}\left(v_{B 1}^{t-1}\right)-F^{*}\left(v_{B 1}^{1}\right) \leq w^{\circ}$. Note that $M I\left[F^{*}(\mathcal{V})\right]=\left[F_{0}(\mathcal{V})\right.$, $\left.F_{\mathbf{w}_{1}}(\mathcal{V})\right] \subset \mathbb{R}_{+}^{n}$ is a continuous segment such that $F_{0}(\mathcal{V})=F^{*}(\mathcal{V}) \in \mathbb{R}_{+}^{n}$. If $\mathbf{e}_{1}\left(\mathbf{a}_{1}\left(h_{t}\right)\right)=\left(\theta_{B 1}^{m_{1}}\right)_{m_{1}=1}^{t-1}$ is the expenditure that $\mathrm{A}$ incurred in political competition game $\Gamma$, given allocation rule $F^{*}(\mathcal{V})$ such that $\theta_{B 1}^{m_{1}}=\theta\left(u_{B 1}^{m_{1}}\left(F^{*}\left(v_{B 1}^{m_{1}}\right)\right)\right)$, let $\geq_{\mathbf{A}}:\left[F_{0}(\mathcal{V}), F_{\mathbf{w}_{1}}(\mathcal{V})\right] \rightarrow\left[F_{0}(\mathcal{V}), F_{\mathbf{w}_{1}}(\mathcal{V})\right]$ be a binary relation on $\left[F_{0}(\mathcal{V}), F_{\mathbf{w}_{1}}(\mathcal{V})\right]$ such that $F_{\lambda}(\mathcal{V}) \geq_{\mathbf{A}} F_{\lambda^{\prime}}(\mathcal{V})$ if and only if $\lambda \geq \lambda^{\prime}$. We say that the wealth that political actor $\mathrm{A}$ wants to expropriate with allocation rule $F_{\lambda}(\mathcal{V})$, given allocation rule $F_{\lambda^{\prime}}(\mathcal{V})$, is equal to $F_{\lambda^{\prime}}(\mathcal{V}) \cdot 1^{\top}-F_{\lambda}(\mathcal{V}) \cdot 1^{\top}$.

Figure 2. Projection of vectors $F_{0}(\mathcal{V})$ and $F_{\mathrm{w}_{1}}(\mathcal{V})$ in their components $\left(F_{\lambda}\left(v_{B 1}^{m_{1}}\right)\right)_{m_{1}=2}^{\mathbf{m}_{1}}$ and $F_{\lambda}\left(v_{B 1}^{1}\right)$ on the plane

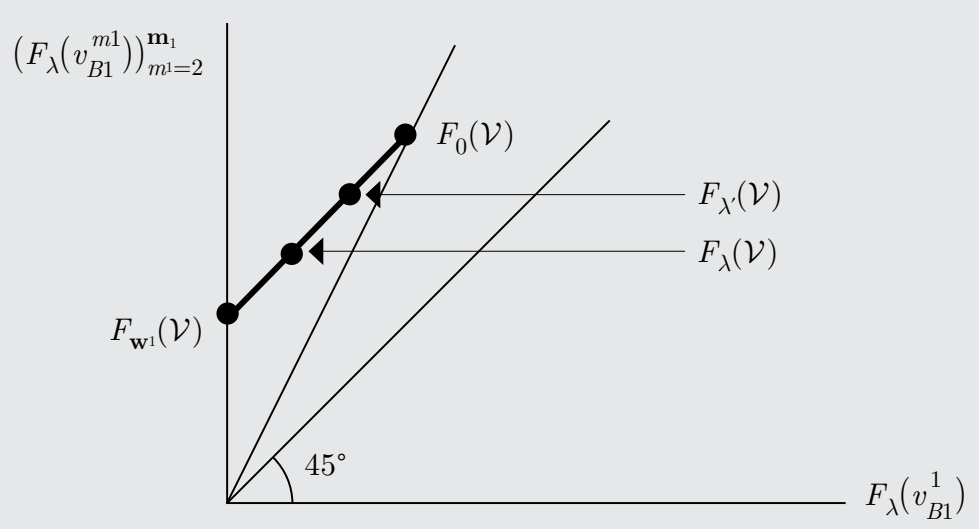

The diagram described shows how the political agenda is a necessary condition, but not a sufficient one, to determine the choice of a certain allocation rule.

Theorem 6. $\geq_{\mathbf{A}}$ is reflexive, transitive, antisymmetric and totally ordered, i.e., $\left[F_{0}(\mathcal{V}), F_{\mathbf{w}_{1}}(\mathcal{V})\right]$ is a totally ordered collection.

Proof. This is trivial once it is satisfied that $\left[0, \mathbf{w}_{1}\right] \subset \mathbb{R}$ is a chain. 
Let $U\left(F_{\lambda}(\mathcal{V})\right)=\left\{F_{\lambda}(\mathcal{V}): F_{\lambda}(\mathcal{V})>_{\mathbf{A}} F_{\lambda}(\mathcal{V})\right\}$ be the upper border of $F_{\lambda}(\mathcal{V}) \in\left[F_{0}(\mathcal{V}), F_{\mathrm{w}_{1}}(\mathcal{V})\right]$ (Border 1985, 32). If exchange network $G_{1}$ does not change and the governing party's objective is to incur an expenditure that is $\mathbf{e}_{1}(t-1)$ less in the next election, then it will seek to execute a political agenda with which it can selectively expropriate from the voting population $\mathcal{V}_{B 1}$. The result of this will be that both income and valuation of the vote of each voter $v \in\left\{v_{B 1}^{m_{1}}\right\}_{m_{1}=1}^{t-1}$ will be very small, i.e., expenditure $\mathbf{e}_{1}(t-1)$ will ostensibly be low in a future election.

Theorem 7. $\left\{F_{\mathbf{w}_{1}}(\mathcal{V})\right\}$ is the U-maximal set of $M I\left[F^{*}(\mathcal{V})\right] \subset \mathcal{F}$.

Proof. We reason by contradiction, and let's assume that $F_{\lambda}(\mathcal{V}) \in U\left(F_{\mathbf{w}_{1}}(\mathcal{V})\right)$ such that $F_{\lambda}(\mathcal{V})>{ }_{\mathbf{A}} F_{\mathbf{w}_{1}}(\mathcal{V})$. Hence, $\lambda>\mathbf{w}_{1}$ and we have arrived at a contradiction, given that $\mathbf{w}_{1}=\max \left[0, \mathbf{w}_{1}\right]$. In consequence, it is not true that $U\left(F_{\mathbf{w}_{1}}(\mathcal{V})\right) \neq \emptyset$.

Hence, if no allocation rule is strictly preferable to $F_{\mathbf{w}_{1}}(\mathcal{V})$ in $\left[F_{0}(\mathcal{V}), F_{\mathbf{w}_{1}}(\mathcal{V})\right]$, then, $\Phi\left(F_{\mathbf{w}_{1}}(\mathcal{V})\right)=\left(\mathbf{W}_{B}^{\prime}, \mathbf{W}_{A}^{\prime}\right)$ is the government's ideal point given that $F_{\lambda}(v)<w^{\circ}$ for all $v \in\left\{v_{B 1}^{m_{1}}\right\}_{m_{1}=1}^{t-1}$, i.e.,

$$
\mathbf{e}_{1}(t-1)=\sum_{m_{1}=1}^{\mathbf{m}_{1}} \theta\left(u_{v}\left(F_{\lambda}\left(v_{B 1}^{m_{1}}\right)\right)\right)=0
$$

If $\Phi\left(F_{\mathbf{w}_{1}}(\mathcal{V})\right)=\left(\mathbf{W}_{B}^{\prime}, \mathbf{W}_{A}^{\prime}\right)$ such that $\mathbf{W}_{A}^{\prime}=\mathbf{W}_{A}$ and $\mathbf{W}_{B}^{\prime}<\mathbf{W}_{B}$ then we can state that $\Phi\left(F_{\mathbf{w}_{1}}(\mathcal{V})\right) \succsim_{\mathbf{A}}\left(\mathbf{W}_{B}, \mathbf{W}_{A}\right)$ for any $\left(\mathbf{W}_{B}, \mathbf{W}_{A}\right) \in \Phi(\mathcal{F})$. Hence, the wealth that political actor A would want to expropriate with allocation rule $\left(\mathbf{W}_{B}^{\prime}, \mathbf{W}_{A}^{\prime}\right)$, given status quo sq, is equal to $\mathbf{W}_{B}-\mathbf{W}_{B}^{\prime}$.

What can we say about political agenda $\sigma^{\prime}$ which induces allocation rule $\left(\mathbf{W}_{B}^{\prime}, \mathbf{W}_{A}^{\prime}\right)$, given bijection $\psi$ ? That political agenda $\sigma^{\prime}$ which the governing party strictly prefers to any other political agenda is that which promotes inadequate and inefficient investment in the provision of public goods for WO individuals in the municipal economy.

It has been demonstrated that if in a non-prioritarian economy the operators of a political party have monopsonist power in the vote market, then ideal point $\mathbf{x}_{\mathbf{A}}=\Phi\left(F_{\mathbf{w}_{1}}(\mathcal{V})\right)$ of the governing party in the political space is located in segment $\left[e_{2} \mathbf{w}_{A}, \mathbf{s q}\right]$. As a consequence, 
Figure 3. Geometric location of the ideal point of the governing party

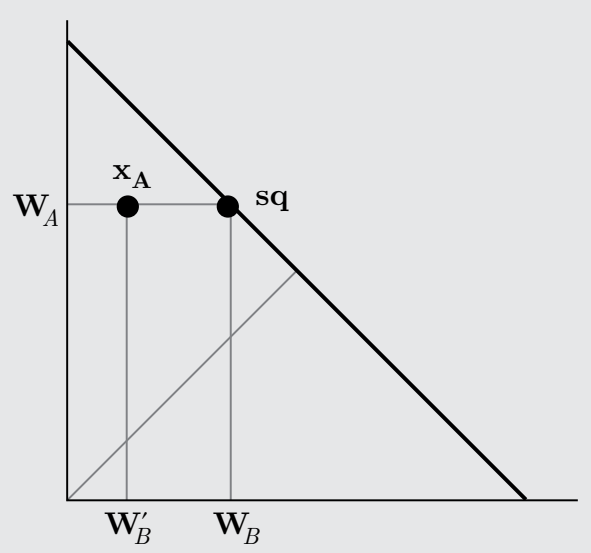

the governing party, that is, the mayor, will promote an ideal political agenda $\sigma_{\mathbf{A}}=\psi\left(\mathbf{x}_{\mathbf{A}}\right)$ in the negotiation of the status quo, and with which there is selective plunder from voter population $\mathcal{V}_{B}$ as the party seeks to confront lower prices in the vote buying market in a future election.

\section{Related Literature}

The literature on vote buying is growing, both because it is a phenomenon that occurs in many countries such as Thailand, Senegal, Taiwan, Mexico and Colombia, and also because it is closely related not only to political clientelism but also to problems of political representation. It is a well-known fact that the clientelist structure of political organizations promotes vote buying through intermediaries (traders) (Wang and Kurzman 2003; Cacliagi and Jun'ichi 2001; Auyero 2000; Muno 2010; Vicente 2010: 2; Kramon 2009: 4).

In particular, and in the context of growth theory, Gersbach and Muhe (2011) establish a very interesting finding: In a democracy in which vote buying is possible, individuals with very low amounts of human capital do not benefit from the education subsidy scheme proposed via referendum. This is so because individuals with high levels of human capital buy the votes required to defeat the proposed political agenda since, if approved, it would impose a tax on their income in order to finance the subsidy program. Because of the defeat of the political 
agenda, individuals with low levels of human capital do not enjoy the conditions for promoting the investment required in education that would enable them to free themselves from their poverty trap.

In developing countries, individuals prefer to sell their vote during elections precisely because they do not perceive that their needs and desires are represented in the political platforms of the parties. A voter prefers to obtain an up-front payment for their vote in a vote market rather than wait for the benefit of a public policy that isn't likely to be implemented. Voters sell their votes because they do not believe that a party represents their needs and desires, not only in the legislative process but also in the design and execution of the political agenda directed by the governing party.

Given the aforementioned, why do Gersbach and Muhe conceive of individuals with low levels of human capital who are willing to sell their votes in a referendum, which is an electoral process in which they themselves legislate with their votes, and therefore, they are not exposed to a situation of moral risk in which their needs and desires are not represented? Because a referendum is a direct representation mechanism, it is a vote and not a party that represents the scheme of a voter's needs and desires. It is not clear why the model proposed by Gersbach and Muhe describes individuals who underestimate the more immediate effects of their vote in a referendum.

On the other hand, the persistence of poverty is not the same as intensification of the same through the continuous looting of public resources by political actors who control the execution of public spending, and who in addition have obtained their positions through vote buying. The inequality described in the growth model proposed by Gersbach and Muhe originates in the rational myopia of individuals with low levels of human capital, and not from the existence of clientelistic political machinery once they surreptitiously sign any number of agreements and negotiations in the legislative and executive arenas.

Dekel, Jackson and Wolinsky (2008),

(...) adopt a model where two parties compete in a binary election and may purchase votes in a sequential bidding game. These authors analyze campaign promises that are contingent on the outcome of the election (what we define as clientelism) and upfront binding payments (what we see as 'enforceable' vote buying). It is found that under campaign promises, total payments received by voters are higher and less widespread than with upfront vote 
buying. Moreover, efficiency is found to be independent from the presence of vote-selling and from the specific forms that it may take (Vicente and Wantchekon 2009:6)

It should be noted that Dekel et al. (2008) consider campaign promises to be a form of payment in vote buying. If a voter does not believe in the political platform announced by a party in its electoral campaign, given that it does not represent their needs and desires, why would the voter believe in the promise of payment from a party without credibility? Moreover, voters are never formalized as players, assuming that each voter sells their vote to the party that makes the highest offer. Why would a party submit its budget to the execution of an expenditure that is increasingly large when competing with its rival party in a contest that pushes the equilibrium price up in the vote market?

Furthermore, why do Dekel et al. (2008) describe a vote market as if it were an auction in which two buyers, two parties, freely take part? This type of description suggests that the voter enjoys a certain power in the social structure of the vote market, or in other words, that the parties compete with one another in an attempt to obtain their vote. Why don't Dekel et al. consider the fact that political machines exercise monopolistic control over the channels, but not over the individuals, through which they engage in exchanges? (Desai 2010, 13).

Moreover, of the studies offered by Robinson and Verdier (2002), Robinson and Torvik (2005), and Keefer and Vlaicu (2008), we highlight the analysis proposed by Robinson and Verdier (2002) for a methodological reason that is important in this article: They establish that the patron-operator relationship is equivalent to the operator-voter relationship. It is unclear why for these authors the patron-operator relationship, which involves informal contracts of personal and political attachment, is a relationship equivalent to the operator-voter relationship, which takes place in a market and in which the payment that the voter receives from the operator never constitutes a favor or hand-out that compromises their freedom or autonomy. It is not in vain that Robinson and Verdier (2002) formally describe the clientelistic structure of the political organization as a network, affirming that the exchange of votes for economic payments or jobs takes place in that network (Robinson and Verdier 2002, 2).

Vicente and Wantchekon's (2009) very comprehensive review of the literature shows how vote buying in a context of networks, in which the patron-client and client-voter relationship are methodologically 
distinguished, has not yet been explicitly explored, nor have its implications for wealth distribution in the very specific context considered in this article. Therefore, the results established in this article are genuinely different from previous findings in the literature.

Voters in Colombia and the political economy. In regard to the behavior of voters in Colombia, Parada (2011) offers a study in which he analyzes

(...) the impact of the voting rule on individual behavior. We use a sample of individuals naturally motivated by real candidates. Then, in our methodology we do not induce preferences (Parada 2011, 79).

In this exercise, Parada relies on Weber and Myerson's (1993) model. This model is part of the family of models arising from the political economy inaugurated by Downs that describes the set of institutional characteristics of politics in the developed West, and where one of its more notable characteristics is the high level of institutional formality of party systems.

Thus, the Weber and Myerson model assumes the existence of political organizations in which the difference between the formal structure and the actual organization is minimal (Freidenberg and Levitsky 2007: 541). In other words, it describes a political system which, in addition to its high degree of institutional sophistication, with no room for mechanisms of political and economic coercion, it only has political actors who are so morally aseptic that they do not become involved in political clientelism, vote buying, electoral system alteration practices, influence trafficking, contracting kickbacks, bribery, payoffs, and looting of public resources.

The administrative practices of local governments that are part of a predatory state, as is the case of the government of Samuel Moreno in Bogotá (Colombia), do not belong to that world described by Weber and Myerson. Parada, in a kind of intellectual initiation rite of ideological duplication that we haven't witnessed, has accepted this world as the place where he resides. This constitutes an asinine act of negation of the exterior world when placed in the immediacy of political and administrative events of recent memory in the Colombian political system.

The statistical analysis offered by Parada is another incursion into the political analysis practices based on the Robinsonian and deinstitutionalized figure of the consumer from microeconomic theory, 
which has been used to construct a certain theory of democracy in political economy. In the words of Weber and Myerson,

Voting equilibria based on polls are somewhat analogous to competitive equilibria based on prices in economic markets. In a pure exchange economy, buyers have preferences for various bundles of commodities. Trading behavior, which generates prices, is driven by the buyers' perceptions of the prices they will confront. At equilibrium, prices summarize demand, and simultaneously generate that same demand. The study of competitive equilibria does not require specification of the precise mechanism by which individual market participants adjust their behavior as the market moves toward equilibrium. Similarly, a detailed model of the process by which a voting equilibrium might be reached is not essential to the definition and computation of voting equilibria (Weber and Myerson 1993: 102).

The use of a model such as that proposed by Weber and Myerson to analyze electoral phenomena in Colombia in particular and in Latin America in general can only be the symptom of a certain class of psychopathology, based on the psychic mechanism of forgetfulness that Freud (1984) analyzed in some modules of his theory of psychoanalysis. Parada's (2011) oversight of the specificities of the behavior of political institutions in Colombia is not merely forgetfulness: it is literally repression. In his intent to avoid touching subjects as thorny as those related to the practices of party systems in Colombia, Parada has repressed his goal of describing those institutional characteristics by choosing to use Weber and Myerson's model. A certain displacement mechanism has been activated in the analysis process that must have led to the construction of a theoretical model that describes that institutional plot in which voters and parties act. This led Parada, unfortunately, toward an erroneous substitute: Weber and Myerson's model.

Orthodox political economy has sought to explain the choice of the set of public policies that make up the status quo in a political system based on the political platforms promoted by the parties in elections. However, there is nothing more distant from Colombia's political and institutional reality. The median voter theorem is flagrant proof of this, as it is used to affirm that "(...) the lower the median voter's income, the greater the state's redistributive tendency" (Moncayo 2006: 176). 
The problem is that in many areas of Colombia, whether municipalities or departments, the lower the income of the median voter, the greater the redistributive trend, but of an inequitable nature (Vieira and Cariboni, 2009). It is strange that Parada is unaware of this, particularly when

(...) inequality in Latin America, measured by the Gini coefficient, is the highest in the world ... and two Andean countries, Bolivia and Colombia, are among those with the greatest concentration (Moncayo 2006: 173).

Why doesn't Parada (2011) look to more recent and pertinent literature on political economy, given that the breakdown of the relationship between inequity and median voter income is a phenomenon that has begun to be recognized in more recent literature and treated with the construction of certain rational choice models? Precisely, Hans Gruner states that

In particular one observes that fiscal variables such as the size of the redistributive government sector are not related to measures of inequality. According to the data, a given unequal distribution may be politically stable even in the presence of large inequalities (Gruner 2009: 240).

However, Gruner seeks to explain the aforementioned breakdown by assuming, based on a standard model of political competition, that voters have the capacity to activate in the parties a certain mechanism of political representation such that they assume that the political platform announced by the party they vote for will be implemented once it becomes the governing party. It is precisely because of this that "political consensus among voters may explain the missing link between inequality and redistribution" (Gruner 2009: 240).

Nevertheless, while it is true that the rupture indicated by Gruner has taken place in Latin America, it is also true that this rupture has taken place within a political system in which the parties, in many areas, do not politically represent the needs and desires of voters.

It should be observed that the political system, as a structure, exhibits properties of a local character in each possible configuration of the party system in each territorial entity, ceteris paribus. This is not taken into account by Parada, who is unaware that the relationship between electoral abstention and the absence of political representation that has arisen in the Colombian political system has no place in 
orthodox political economy: the school of which he has decided to be a judicious user. What is ironic is that the militants of orthodox political economy themselves have taken it upon themselves to show that models that admitted the existence of the political abstention phenomenon in the presence of political representation were poorly constructed in methodological terms.

In effect, the standard political economy models that involve the abstention phenomenon, whether from the rational choice hypothesis or uncertainty about vote behavior (Ledyard, 1984), do so based on certain considerations about the relationship between the voting expense and the expected utility hypothesis (Ferejohn and Fiorina 1974). Thus, many authors have reached a disturbing conclusion in the context of abstentionist models: No rational voter votes in elections with a very large number of voters, as the expected benefit is strictly lower than the cost involved in going out to vote.

This is an abstention that appears as a result of the belief of each individual regarding the decisiveness of their vote, and not based on the perception of whether one is politically represented by the party and the political platform to which they would allocate their vote (Roemer 2001; Chamberlain and Rothschild 1981). Nevertheless, Ledyard (1984) indicated that the hypotheses supporting these models were posed incorrectly in the theory. He observed that although the conclusion was still reasonable - in terms of the consistency of the chain of logical reasoning - the analysis was incomplete, as it was based on a perspective of partial equilibrium, making it inappropriate. In a general equilibrium model, Ledyard (1984: 12) shows that the apparent failure of rational choice to explain voting disappears.

Ethnography and political science should be required fields of consideration when exploring research subjects that are not exclusive to economic theory. This is because what the ethnography of voter behavior in Colombia has shown in the departments of Chocó or Atlántico, for example, is that the willingness of the average voter to sell their vote is very high as long as the crisis of political representation in which the parties are submerged, locally speaking, is indisputable (Betancurth, 2011; Sánchez and Espejo, 2009; El Nuevo Diario, 2010; El Mundo, 2011).

In these territories, the parties can only obtain the vote of a voter if they offer an adequate economic consideration, not necessarily 
monetary, in return. Precisely, in the department of Chocó (Colombia), a voter states that given that

(...) the governor does not fulfill their promise, they should pay for the vote. They say: 'Give me a little something,' knowing that 'that little something doesn't even get us out of this morass, nor will it make the politician accountable in the future,' Mena says about the electoral reality in the black communities of the Atrato River, which crosses Chocó from south to north on its way to the Caribbean Sea" (Vieira and Cariboni, 2009).

Ethnography repeatedly shows that voters in many Colombian territories act with a level of rationality very different from that assumed by Parada, to the point that

The director of the Electoral Observation Mission, Alejandra Barrios, stated in a press conference that they determined that in San Onofre, some 584 kilometers northeast of Bogotá, voters requested money, about 100,000 pesos (50 dollars) after voting for candidates of parties such as Apertura Liberal (El Universal, 2010).

Is it the case that the average voter in the Chocó department, when allocating their vote to a candidate, is thinking something similar to the voting rules that Parada considers in his simulation? Each "voting rule" is a criterion with such a degree of sophistication for the population of Chocó that it would seem to exist only in the illusory representation that Parada has constructed of voters in some possible - or perhaps impossible - world of a Colombian political system, a world inhabited by 455 survey subjects and built on a sampling exercise that is poorly designed in a technical sense.

In effect, the sampling exercise carried out by Parada flagrantly violates the equiprobability criterion: Were the voters who sell their votes in certain regions of the Colombian Atlantic and Pacific coasts, as is well documented, considered by Parada (2011: 86) when designing his sampling technique? It is difficult to believe now that among canoes, fishing nets, guerrillas, mosquitoes, misery and all types of bandits, the voters of Chocó, who just three years ago saw their infants dying due to lack of access to basic healthcare services that resulted from political corruption, have had some probability of being surveyed, even though it is technically impossible for them to obtain access to the information technologies that Parada used. 
Why is it that this type of voter, whose preferences for political candidates do not matter because they simply do not believe in the political platforms they promote, have not had the same probability of being surveyed by Parada? If we use a formal argument as a metaphor, what Parada has done is the following:

If $\mathbb{Q}$ is the set of voters in Colombia, he has proposed to say something about the behavior of the elements in $\mathbb{Q}$, while studying the behavior of the elements of a sample $X$ based on a model that only describes $\mathbb{Z} \subset \mathbb{Q}$, which is, in the proposed metaphor, a set of voters with the characteristics of the voters described in the model of Weber and Myerson (1993). Therefore, $\mathbb{Q}-\mathbb{Z}$ is a set of voters who, before voting based on their preferences, cast their votes based on negotiations, clientelism, and political and economic coercion. The problem is that Parada builds a sample $X$ such that $X \subset \mathbb{Z}$. Parada would say: "I will not induce any preference in each element of $\mathbb{Q}$, however (and here the trap in his argument appears) and given that my model only describes $\mathbb{Z}$, I have only chosen voters who live in $\mathbb{Z}$ ". Second, he would find as a result, after having testing his null hypothesis $H_{0}: \mathbb{Q}$ is not dense, that there is insufficient statistical information to reject it.

Obviously, he does not offer deductive demonstrations, given that the model describes only $\mathbb{Z}$, does not enable him to construct any statement about $\mathbb{Q}$, and in a juggling act fit for an acrobat, he offers "proof" of rigor based on certain statistical manipulations, concluding that $\mathbb{Q}$ is not dense because "the data say so." As if the model of $\mathbb{Z} \subset \mathbb{Q}$ allows for saying something about $\mathbb{Q}$, and even more seriously, as if the hypothesis tests establish the true status of certain statements that can only be constructed deductively in the logical language. The hypothesis tests do not establish anything; they only verify that the theoretical hypotheses built on a theory can be temporarily sustained as long as there is insufficient information available to reject them. The reasonings don't begin with the data; they begin with the theories and logical-deductive apparatuses that theoretical economists construct. The problem is that Parada attempts to make statements about $\mathbb{Q}$ following a model that only describes $\mathbb{Z}$. If Parada wants to say something about $\mathbb{Q}$ he should, on the one hand, have a model that describes $\mathbb{Q}$ and not just $\mathbb{Z}$, and on the other hand, build representative samples in which each element of $\mathbb{Q}$ has the probability of being chosen, instead of choosing only elements that live in $\mathbb{Z}$, as if political representation were a quality of the political system in each territorial entity in Colombia. 
Not in vain, one of the most prominent political science theorists in Colombia has said that "the main criticism directed at contemporary political parties is centered around their representative function, or more specifically, their failure to satisfactorily represent civil society in government agencies" (Hoskin 2011: 295).

This is a failure that, among other considerations, is due to the fact that parties in Latin America are not highly formalized. Thus, a model such as that chosen by Parada (2011) for his simulation is inappropriate, as it assumes "(...) that the parties are organized as set out in their statutes. These assumptions don't go far in Latin America. The difference between the way in which parties are organized in their statutes and how they function in practice is enormous" (Freidenberg and Levistski 2007: 540).

In the words of Prats (2004), "In Latin America, almost nothing is what it appears to be because, in many spheres, institutional informality clearly prevails, sometimes in contradiction with the formality that it annuls and substitutes the facts" (Prats, 2004).

Therefore, if Parada sustains that "In this document we focus our attention on the social decision making process in democracies" (Parada 2011: 81) then, his analysis is methodologically stale, as it is built on the basis of a model in which it is not known that

In Latin America there are formally organized parties as well as informal ones. Many are even structured along the lines of their counterparts in Europe, but there is a significant vacuum within this organization. The formal organization and the real one are quite different, so much that when observing each one, they seem to be different parties (Freidenberg and Levistski 2007: 541).

The critique of Parada does not originate in the fact that we have different theoretical affiliations, and less on an arbitrary criterion for judging the unsuitability of his analysis. On the contrary, the critique of Parada and the statistical work style he represents arises from the fact that he ignores basic criteria established in the logic and methodology of economics. In effect, if the platforms promoted by the parties are credible political agendas, then, a voter allocates their vote to a party based on their preferences over the set of political platforms. Hence, it is generally not true that if the platforms promoted by the parties are not credible political agendas that an individual votes according to their preferences over the set of political platforms, given that a basic fact of logic establishes that any statement, whether true or false, can be established from a false hypothesis. 
Why does Parada maintain a representation of the political world in which voters act in a sophisticated manner in accordance with Weber and Myerson's model? Simply because he believes, consciously or not, naively or not, that political parties represent the spectrum of voter needs and desires in many parts of Colombia. The set of Downsonian political economy models constitutes Parada's intellectual prison.

The most recent studies and strict rigor in Latin American political science show precisely that party political platforms are agendas that are not credible if they are established based on clientelist criteria. It appears that Parada is unaware of the fact that decisions about municipal public spending, which are eminently political-regarding how to distribute, execute and set the amount of the budget to finance it - do not depend, in many of Colombia's municipalities, on the criteria of rationality or political representation that the decision models assume to guide the behavior of a local government as a decision agent.

Rather than obeying criteria of economic efficiency or political representation of the bases that voted for the governing party, decisions about public spending instead follow rationality criteria based on certain ideological positions that, situated in the political space, are the expression of the system of objectives that formal or informal political organizations seek to promote consistently, abetted by the political institutions of a political and party system.

The analysis offered by Parada is an unfortunate episode in the history of political analysis that exists in the gap between Latin American political science and political economy. If simulations continue to be constructed based on models that openly ignore both ethnography regarding electoral behavior in Colombia and the institutional conditions under which local governments are situated as decision agents, they will manifest the stagnation of Latin American political thought promoted by those empirical economists who, rather than create theoretical models appropriate to the region and its politics, live under the effects of a kind of spell in which they seek to practice unhealthy econometric and statistical acrobatics, based on a certain type of formal virtuosity that is not very formal, and with which power, as a subject of study, disappears in a political economy without politics $^{24}$. In the words of Federico Vallejo, 
(...) it is not surprising in a post-modern age where, as Beatriz Valencia (a poet living in Antioquia) says with elegant black humor: "Postmodernity manifests things without their essence: Sugar-free desserts, decaffeinated coffee, non-alcoholic beer...". Along with Beatriz, we also say that, in the postmodern language and (from there), the intellectual "products" that are generated have also appeared lacking in essence : economics without politics - as is the case of the neoclassicals and their attempt at scientific objectivity - public policies that increasingly appear without the (implicit but not evident) action of the government, democracies without social classes, and a very long etcetera (Vallejo 2010: 20).

Likewise, Tsebelis (2000) observed that "the analysis of rational choice was completely established in U.S. politics, but completely underdeveloped in comparative politics" (Tsebelis 2000: 34).

It should also be observed that the analysis of rational choice is completely underdeveloped in the field of Latin American political economy, even though it has begun to be built by highly intelligent economists such as Saiegh and Tomassi (1998). 


\section{REFERENCES}

Auyero, J. (2000), "The Logic of Clientelism in Argentina: An Ethnographic Account." Latin American Research Review, Vol. 35, No. 3: 55-81.

Barco, C. and V. Jaramillo, (2005), Votar o no votar, esa es la cuestión. La abstención política, una constante en el comportamiento ciudadano en la historia democrática colombiana [To vote or not to vote, that is the question. Political abstention, a constant of citizen behavior in Colombia's democratic history]. Mimeo. Caldas, Colombia: Centro de Investigaciones Sociojurídicas (CIS), Universidad de Caldas.

Betancurth, M. (2011), "40 mil pesos por voto ¿Usted lo vendería?" $[40,000$ pesos for your vote: would you sell it?] Revista Gobierno. http://www. revistagobierno.com/portal/index.php/politica/91-elecciones-2011-/836140-mil-pesos-por-voto-iusted-lo-venderia (retrieved Oct., 2012).

Blume, L., D. Easley, J. Kleinberg, and E. Tardos (2007), "Trading Networks with Price-Setting Agents." Games and Economic Behavior, Vol. 67: 36-50.

Border, K. (1985), Fixed Point Theorems with Applications to Economics and Game Theory. Cambridge: Cambridge University Press.

Caciagli, M. and K. Jun'ichi (2001), "Heurs et Malheurs du Clientélisme. Etude Comparée de l'Italie et du Japon." Revue française de science politique, Vol. 51, No. 4: 569-586.

Chamberlain, G. and M. Rothschild (1981), "A Note on the Probability of Casting a Decisive Vote." Journal of Economic Theory, Vol. 25: 152-162.

Desai, R. (2010), "The Political Economy of Urban Poverty in Developing Countries." Wolfensohn Center for Development Working Papers 20.

Dekel, E., M. Jackson and A. Wolinsky (2008), "Vote Buying: General Elections." The Journal of Political Economy, Vol. 116, No 2: 351-380.

El Nuevo Diario (2010), "Denuncian compra de votos en legislativas de Colombia" [Vote buying reported in Colombian legislative elections]. http://www. elnuevodiario.com.ni/internacionales/70169 (retrieved Oct., 2012).

El Mundo (2011), Un candidato colombiano denuncia compra de votos con marihuana [Colombian candidate makes accusations of vote buying with marijuana]. http://www.elmundo.es/america/2011/08-/30/colom- bia/1314736152.html.

El Universal (2010). http://www.eluniversal.com/2010/03/14/i- nt_ava_observadores-elector_14A3584011.shtml.

Fan, S., L. Zhang and X. Zhang (2002), "Growth, Inequality, and Poverty in Rural China: The Role of Public Investments." Washington, D.C.: Research Report No. 125, International Food Policy Research Institute.

Ferejohn, J. and M. Fiorina (1974), "The Paradox of Not Voting: A Decision Theoretic Analysis." The American Political Science Review, Vol. 63: 525-536.

Fleurbaey, M., B. Tungodden, and P. Vallentyne (2008), "On the Possibility of Nonaggregative Priority for the Worst Off." Social Philosophy and Policy, Vol. 26: 258-285. 
Freidenberg, F. (2002), "Incentivos electorales y selección de candidatos en organizaciones neopopulistas: El Partido Roldosista Ecuatoriano (19842000)" [Electoral incentives and selection of candidates in neopopulist organizations: The Roldosista Ecuatoriano Party (1984-2000)]. Ciencias de Gobierno, Vol. 12: 32-62.

Freidenberg, F. and S. Levitsky (2007), "Organización informal de los partidos en América Latina" [Informal organization of parties in Latin America]. Desarrollo Económico, Vol. 46, No. 184: pp. 539-568.

Freud, S. (1984), Psicopatología de la vida cotidiana [The psychopathology of everday life]. Bogotá: Editorial printer Colombiana Ltda.

Gersbach, H. and F. Muhe (2011), "Vote-buying and Growth". Macroeconomics Dynamics, Vol. 15, Issue 5: 656-680.

García-Pérez, L. I. and A. Villar (2009), "Discrimination and Equality of Opportunity." Universidad Pablo de Olavide Working Papers.

Gruner, H. (2009), "Inequality and political consensus". Theory and Decision, Vol. 67: 239-265.

Hicken, A. (2002), "The Market for Votes in Thailand." Prepared for delivery at international conference on "Trading Political Rights: The Comparative Politics of Vote Buying." Center for International Studies, MIT, 2002.

Hoskin, G. (2011), "El estado y los partidos políticos en Colombia" [The state and political parties in Colombia]. In F. Botero, ed., Partidos y elecciones en Colombia [Parties and elections in Colombia]. Bogotá: Ediciones Uniandes.

Keefer, P. and R. Vlaicu (2008), "Democracy, Credibility and Clientelism." Journal of Law, Economics, and Organization, Vol. 24, No. 2: 371-406.

Kramon, E. (2009), "Vote Buying and Turnout in Kenya's 2002 Elections." Mimeo. African Politics Reading Group, University of California, Los Angeles.

Ledyard, J. (1984), "The pure theory of large two-candidate elections." Public Choice Vol. 44, No. 1: 7-41.

La Patria. (2010). http://www.lapatria.com.co/story/la-u-investigarC-3A1-si-ensus-filas-hubo-compra-de-votos.

Moncayo, E. (2006), "Relaciones entre democracia y desarrollo en los países andinos. Una reflexión desde la economía política" [Relationships between democracy and development in the Andean countries: A reflection from political economy]. Revista de Economía Institucional, Vol. 8, No. 14.

Montealegre, E. (2006), Constitución y vivienda. Estudio sobre la liquidación y reliquidación de los créditos de vivienda en los sistemas UPAC y UVR [Constitution and housing: Study of payment and repayment of housing loans in the UPAC and UVR systems]. 74/Temas de Derecho Público. Bogotá: Universidad Externado de Colombia.

Moreno-Ternero, J.D. and J. Roemer (2006), "Impartiality, Solidarity and Priority in the Theory of Justice." Econometrica Vol. 74, No. 5: 1419-1427.

Moser, C. (2008), "Poverty Reduction, Patronage, or Vote Buying? The Allocation of Public Goods and the 2001 Election in Madagascar." Economic Development and Cultural Change Vol. 57: 137-162. 
Muno, W. (2010), "Conceptualizing and Measuring Clientelism." Paper to be presented at the workshop on Neopatrimonialism in Various World Regions, GIGA German Institute of Global and Area Studies, Hamburg.

Myerson, R. and R. Weber (1993), "A theory of voting equilibria." American Political Science Review Vol. 87: 102-114.

Parada, J. (2011), "Voters' Rationality Under Four Electoral Rules: A Simulation Based on the 2010 Colombian Presidential Elections." Revista Desarrollo y Sociedad No. 68.

Peragine, V. (2000), "Opportunity, Responsibility and the Ranking of Income Distributions." Mimeo. Universidad Carlos III Working Paper 00-03.

Peragine, V. (2002), "Opportunity, Egalitarianism and Income Inequality." Mathematical Social Sciences Vol. 44: 45-64.

Prats, J. (2004), "Gobernabilidad para el desarrollo. Propuesta de un marco conceptual y analítico" [Governance for development: Proposal for a conceptual and analytical framework]. In C. Binetti and F. Carrillo, eds., ¿Democracia con desigualdad? Una mirada de Europa hacia América Latina [Democracy with inequality? A European perspective on Latin America]. Bogotá: Inter-American Development Bank, European Union and Alfaomega.

Rehren A. (2000), "Clientelismo político, corrupción y reforma del estado en Chile." Tinker Foundation Working Paper No. 305, New York.

Revista Gobierno (2011), "Compra de votos. Una amenaza" [Votebuying: A threat]. http://www-.revistagobierno.com/portal/index. php?option $=$ com content\&view $=$ article- $\&$ id $=5693$ :compra-de-votos-unaamenaza\&catid $=\overline{9} 1$ :elecciones-2011-\&Itemi- $\mathrm{d}=91$.

Robinson, J. and R. Torvik (2005), "White Elephants". Journal of Public Economics Vol. 89: 197-210.

Robinson, J. and T. Verdier (2002), "The Political Economy of Clientelism." CEPR Working Paper 3205.

Roemer, J. (2004), "Eclectic distributional ethics." Mimeo. Yale University.

Roemer, J. (2001), Political Competition: Theory and Applications. Cambridge: Harvard University Press.

Ruiz Castillo, J. (2003), "The Measurement of Inequality of Opportunities." In. Bishop, J. and Y. Amiel, eds., Research in Economic Inequality Vol. 9: 1-34.

Saiegh, S. and M. Tomassi (1998), "La nueva economía política. Racionalidad e instituciones" [The new political economy: rationality and institutions]. Document 10, Fundación Gobierno y Sociedad.

Sánchez, J. and C. Espejo (2009), "La compra de votos llegó a Bogotá: ofrecen hasta 50 millones a líderes por sus votos [Vote-buying reaches Bogotá: leaders offered as much as 50 million for their votes]. El Tiempo. http:// www.eltiempo.com/archivo- /documento/CMS-3755834.

Schaffer, F. (2006), "What is Vote Buying?" In Schaffer, F., ed., Elections for Sale: The Causes and Consequences of Vote Buying. Boulder, Colo. and London: Lynne Rienner Publishers. 
Vallejo, F. (2001), "Sobre la 'gobernabilidad democrática' en la era de la 'globalización'" [On democratic governance in the era of globalization]. In ¿Cuál sujeto pedagógico? Medellín: Editorial Benitez yAsociados.

Vallentyne, P. (2000), "Equality, Efficiency, and the Priority of the Worse Off." Economics and Philosophy Vol. 16: 1-19.

Vicente, P. (2010), "Is Vote-buying Effective? Evidence from a Field Experiment in West Africa." University of Oxford.

Vicente, P. and L. Wantchekon, L. (2009). "Clientelism and Vote Buying: Lessons from Field Experiments in African Elections." Mimeo. University of Oxford.

Vieira, C. and D. Cariboni (2009), "Elections-Colombia: The Going Rate for Votes." Inter Press Service News Agency. http://ipsnews.net/news. asp?idnews $=39844$.

Villar, A. (2005), "On the Welfare Measurement of Income and Opportunity." Contributions to Theoretical Economics, Vol. 5.

Volintiru, C. (2010), "Clientelism and Democratic Accountability." Political Studies Association Graduate Network Conference.

Wang, C. S. and C. Kurzman (2003), "Logistics: How to Buy Votes." Mimeo. University of North Carolina. 


\section{APPENDIX}

\section{A. Proof of Theorem 1}

If $B^{i}>>B^{-i}$ if and only if $A_{-i, \tau} \subset A_{i, \tau-1}$ for all $\tau \in \mathbb{Z}_{+}-\{1\}$, then, party $i$ wins the political competition such that $L_{-i, t}\left(\left\langle\mathcal{L}_{i}, \mathcal{L}_{-i}\right\rangle\right) \notin A_{-i, t}$ and $a_{-i, \tau}=0$. If $\mathbf{a}_{i}\left(\left\langle\mathcal{L}_{i}, \mathcal{L}_{-i}\right\rangle\right)=\mathbf{a}_{i}\left(h_{t}\right)$ and $\mathbf{a}_{i}\left(h_{t-1}\right)=\mathbf{a}_{i}\left(h_{t}\right)$, then, given strategy $\mathcal{L}_{-i}$, it holds that

$W-\mathbf{e}_{i}\left(\mathbf{a}_{i}^{*}\left(\left\langle\mathcal{L}_{i}^{*}, \mathcal{L}_{-i}\right\rangle\right)\right)>W-\mathbf{e}_{i}\left(\mathbf{a}_{i}\left(\left\langle\mathcal{L}_{i}, \mathcal{L}_{-i}\right\rangle\right)\right)$

for any $\mathcal{L}_{i} \neq \mathcal{L}_{i}^{*}$ if and only if $\mathbf{e}_{i}\left(\mathbf{a}_{i}^{*}\left(\left\langle\mathcal{L}_{i}^{*}, \mathcal{L}_{-i}\right\rangle\right)\right)<\mathbf{e}_{i}\left(\mathbf{a}_{i}\left(\left\langle\mathcal{L}_{i}, \mathcal{L}_{-i}\right\rangle\right)\right)$ for any $\mathcal{L}_{i} \neq \mathcal{L}_{i}^{*}$. Hence, if $\mathbf{e}_{i}$ is increasing and $\mathcal{L}_{-i}$ is fixed, if $i$ does not know $\max A_{-i, \tau}$ them party $i$ minimizes expenditure $\mathbf{e}_{i}(\cdot)$ if

$\mathbf{a}_{i}^{*}\left(\left\langle\mathcal{L}_{i}^{*}, \mathcal{L}_{-i}\right\rangle\right)=\mathbf{a}_{i}\left(h_{t-3}\right)+a_{i, t-1}$

such that $a_{i, t-1} \leq \bar{a}_{-i, t}$ and $\bar{a}_{-i, t}<L_{-i, t}\left(h_{t-1}\right)$.

\section{B. Proof of Theorem 2}

Case 1. $B^{1}>>B^{2}$. Let us prove $\mathcal{L}_{1}^{*}$ is weakly dominant in the set of histories $H_{t}$ such that $\left|h_{t}\right|=t \in 2 \mathbb{Z}_{+}$for any $h_{t} \in H_{t}$, i.e., let us prove that $\mathcal{L}_{1}^{*}$ is weakly dominant in the set of histories $H_{t}$ in which party 1 wins the political competition. Let $\mathcal{L}_{1}=\left(L_{1, \tau}\right)_{\tau=1}^{\infty}$ be any strategy such that $\mathcal{L}_{1} \neq \mathcal{L}_{1}^{*}$; hence, there is at least one $\mathbf{s} \in 1+2 \mathbb{Z}_{+}$such that $L_{1, \mathbf{s}} \neq L_{1, \mathbf{s}}^{*}$ - Note that $1+2 \mathbb{Z}_{+}$denotes the set of uneven and positive integers.

Let us assume that there is a fixed uneven number $\mathbf{t}+1 \in 1+2 \mathbb{Z}_{+}$such that $L_{1, \tau}\left(h_{\tau-1}\right)=L_{1, \tau}^{*}\left(h_{\tau-1}\right)$ for all $\tau \in[1+2 \mathbb{Z}]-\{\mathbf{t}+1\}$ and

$L_{1, t+1}\left(h_{t}\right)=\left\{\begin{array}{ccc}a_{1, t+1}>\left[\mathbf{a}_{2}\left(h_{\mathrm{t}}\right)-\mathbf{a}_{1}\left(h_{t-1}\right)\right]+1 & \text { si } & a_{1, t+1} \in A_{1, \tau} \\ 0 & \text { si } & a_{1, t+1} \notin A_{1, \tau}\end{array}\right\}$

Case 1.1. Party 2 follows a strategy $\mathcal{L}_{2}$ such that $h_{t}=\left\langle\mathcal{L}_{1}, \mathcal{L}_{2}\right\rangle$ and $h_{s}=\left\langle\mathcal{L}_{1}, \mathcal{L}_{2}\right\rangle$ are histories of length strictly less than $\mathbf{t}+1$, i.e., $\left|h_{t}\right|=t<\mathbf{t}+1$ and $\left|h_{s}\right|=s<\mathbf{t}+1$. Hence, given strategy $\mathcal{L}_{2}$, party 1 does not apply decision rule $L_{1, \mathbf{t}+1}\left(h_{t}\right)$ from its strategy $\mathcal{L}_{1}$. If $L_{1, \tau}=L_{1, \tau}^{*}$ for all $\tau \in 1+2 \mathbb{Z}_{+}$such that $\tau<\mathbf{t}+1, h_{t}=\left\langle\mathcal{L}_{1}, \mathcal{L}_{2}\right\rangle$ and $h_{s}=\left\langle\mathcal{L}_{1}^{*}, \mathcal{L}_{2}\right\rangle$, then $h_{t}=h_{s}$ and $s=t$. Hence, $v_{1}\left(h_{t}\right)=v_{1}\left(h_{s}\right)$. 
Case 1.2. Party 2 follows a strategy $\mathcal{L}_{2}$ such that $\left|h_{t}\right|=\left|h_{s}\right|=\mathbf{t}+2$. Hence, $L_{1, \tau}=L_{1, \tau}^{*}$ for any $\tau \in[1+2 \mathbb{Z}]-\{\mathbf{t}+1\}$ and $L_{1, \mathbf{t}+1}>L_{1, \mathbf{t}+1}^{*}$ given that $t-1=s-1=\mathbf{t}+1$. If $L_{1, \tau}>L_{1, \tau}^{*}$ for any $\tau \in 1+2 \mathbb{Z}$ such that $\tau \leq \mathbf{t}-1=t-3$ then $\mathbf{a}_{1}\left(h_{t-3}\right)=\mathbf{a}_{1}\left(h_{s-3}\right)$. Hence, if $t=s$ then $\mathbf{e}_{1}\left(\mathbf{a}_{1}\left(h_{t-3}\right)\right)=\mathbf{e}_{1}\left(\mathbf{a}_{1}\left(h_{s-3}\right)\right)$ by definition of function. On the other hand, if $e_{1, t-1}=e_{1, s-1}$ and $a_{1, t-1}>a_{1, s-1}$ such that $L_{1, t-1}\left(h_{t-2}\right)=a_{1, t-1}$ and $L_{1, s-1}^{*}\left(h_{s-2}\right)=a_{1, s-1}$, then, $e_{1, t-1}\left(a_{1, t-1}\right) \geq e_{1, s-1}\left(a_{1, s-1}\right)$ given that $e_{1, t-1} \geq e_{1, s-1}$ is an increasing function. Thus, if $\mathbf{a}_{1}\left(h_{t-3}\right)=\mathbf{a}_{1}\left(h_{s-3}\right)$ and $a_{1, t-1}>a_{1, s-1}$ then

$\mathbf{a}_{1}\left(h_{t-3}\right)+a_{1, t-1}=\mathbf{a}_{1}\left(h_{t-1}\right)>\mathbf{a}_{1}\left(h_{s-1}\right)=\mathbf{a}_{1}\left(h_{s-3}\right)+a_{1, s-1}$

Hence,

$\mathbf{e}_{1}\left(\mathbf{a}_{1}\left(h_{t-1}\right)\right) \geq \mathbf{e}_{1}\left(\mathbf{a}_{1}\left(h_{s-1}\right)\right)$.

Note that

$h_{s}=h_{s-2} \cdot\left(a_{1, s-1}, 0\right)$

and

$h_{t}=h_{t-2} \cdot\left(a_{1, t-1}, 0\right)$

such that $h_{t-2}=h_{s-2}$ and $a_{1, t-1} \neq a_{1, s-1}$. Its hold that $h_{t}$ and $h_{s}$, as histories of equal length, are different when the decision taken in the second-to-the-last stage is different in both histories. Hence, if $\mathbf{e}_{1}\left(\mathbf{a}_{1}\left(h_{t-1}\right)\right) \geq \mathbf{e}_{1}\left(\mathbf{a}_{1}\left(h_{s-1}\right)\right)$ then

$W-\mathbf{e}_{1}\left(\mathbf{a}_{1}\left(h_{t-1}\right)\right)<W-\mathbf{e}_{1}\left(\mathbf{a}_{1}\left(h_{s-1}\right)\right)$

In consequence, $v_{1}\left(h_{s}\right)>v_{1}\left(h_{t}\right)$.

Case 1.3. Party 2 follows a strategy $\mathcal{L}_{2}$ such that $\left|h_{t}\right|-1>\mathbf{t}+1$ and $\left|h_{s}\right|-1>\mathbf{t}+1$. Hence, given strategy $\mathcal{L}_{2}$, party 1 applies decision rule $L_{1, \mathbf{t}+1}\left(h_{\mathbf{t}}\right)$ from its strategy $\mathcal{L}_{1}$ in a stage prior to the second-to-last stage of $h_{t}$ and $h_{s}$. For the analysis of this case, we will require the following lemma.

Lemma A. If party 1 follows its investigative strategy $\mathcal{L}_{1}^{*}$, then, $\mathbf{a}_{2}\left(h_{\mathbf{t}-2}\right)+1=\mathbf{a}_{1}\left(h_{\mathbf{t}-1}\right)$.

Proof. We have that $L_{1, \tau}^{*}\left(h_{\tau-1}\right)=\left[\mathbf{a}_{2}\left(h_{\tau-1}\right)-\mathbf{a}_{1}\left(h_{\tau-2}\right)\right]+1$ by definition of $L_{1, \tau}^{*}\left(h_{\tau-1}\right)$. But

$\mathbf{a}_{2}\left(h_{\tau-1}\right)=\mathbf{a}_{2}\left(h_{\tau-3}\right)+a_{2}\left(h_{\tau-1}\right)$ 
and

$\mathbf{a}_{1}\left(h_{\tau-2}\right)=\mathbf{a}_{1}\left(h_{\tau-4}\right)+a_{1}\left(h_{\tau-2}\right)$

In consequence,

$$
\begin{aligned}
L_{1, \tau}^{*}\left(h_{\tau-1}\right) & =\left[\left(\mathbf{a}_{2}\left(h_{\tau-3}\right)+a_{2}\left(h_{\tau-1}\right)\right)-\left(\mathbf{a}_{1}\left(h_{\tau-4}\right)+a_{1}\left(h_{\tau-2}\right)\right)\right]+1 \\
& =\left[\left(\mathbf{a}_{2}\left(h_{\tau-3}\right)-\mathbf{a}_{1}\left(h_{\tau-4}\right)\right]+1+a_{2}\left(h_{\tau-1}\right)-a_{1}\left(h_{\tau-2}\right)\right.
\end{aligned}
$$

But

$L_{1, \tau-2}^{*}\left(h_{\tau-3}\right)=\left[\mathbf{a}_{2}\left(h_{\tau-3}\right)-\mathbf{a}_{1}\left(h_{\tau-4}\right)\right]+1$

by definition of $L_{1, \tau-2}^{*}$. Therefore,

$$
\begin{aligned}
L_{1, \tau}^{*}\left(h_{\tau-1}\right) & =L_{1, \tau-2}^{*}\left(h_{\tau-3}\right)+a_{2}\left(h_{\tau-1}\right)-a_{1}\left(h_{\tau-2}\right) \\
& =a_{1}\left(h_{\tau-2}\right)+a_{2}\left(h_{\tau-1}\right)-a_{1}\left(h_{\tau-2}\right) \\
& =a_{2}\left(h_{\tau-1}\right) ; \tau \geq 3
\end{aligned}
$$

Hence, if $L_{1,1}^{*}\left(h_{0}\right)=a_{11}=1$ and $L_{1, \tau}^{*}\left(h_{\tau-1}\right)=a_{2, \tau-1}$ for any $\tau \in[1+2 \mathbb{Z}]-\{\mathbf{t}+1\}$, then,

$$
\begin{aligned}
\mathbf{a}_{1, \mathbf{t}-1} & =a_{1,1}+a_{1,3}+\ldots+a_{1, \mathbf{t}-1} \\
& =1+a_{2,2}+\ldots+a_{1, \mathbf{t}-2} \\
& =1+\mathbf{a}_{2}\left(h_{\mathbf{t}-2}\right)
\end{aligned}
$$

In consequence, $\mathbf{a}_{2}\left(h_{\mathbf{t}-2}\right)+1=\mathbf{a}_{1}\left(h_{\mathbf{t}-1}\right)$.

If $h_{t}=\left\langle\mathcal{L}_{1}, \mathcal{L}_{2}\right\rangle$ then

$h_{t}\left\lceil A_{1}=\left(1, \ldots, a_{1, \mathbf{t}-1}, a_{1, \mathbf{t}+1}, a_{1, \mathbf{t}+3}, \ldots, a_{1, \mathbf{t}-1}\right)\right.$

such that $L_{t, \tau}\left(h_{\tau-1}\right)=L_{1, \tau}^{*}\left(h_{\tau-1}\right)$ for any $\tau \in\left[1+2 \mathbb{Z}_{+}\right]-\{\mathbf{t}+1\}$ and $L_{1, \mathbf{t}+1}\left(h_{\mathbf{t}}\right)>L_{1, \mathbf{t}+1}^{*}\left(h_{\mathbf{t}}\right)$. Hence,

$\mathbf{a}_{1}\left(h_{t-1}\right)=\mathbf{a}_{1}\left(h_{\mathbf{t}-1}\right)+a_{1, \mathbf{t}+1}+a_{1, \mathbf{t}+3}+\left[\mathbf{a}_{1}\left(h_{t-1}\right)-\mathbf{a}_{1}\left(h_{\mathbf{t}+3}\right)\right]$

Calculating $a_{1, \mathbf{t}+3}$ we have that

$$
\begin{aligned}
a_{1, \mathbf{t}+3} & =L_{1, \mathbf{t}+3}^{*}\left(h_{\mathbf{t}+2}\right) \\
& =\left[\mathbf{a}_{2}\left(h_{\mathbf{t}+2}\right)-\mathbf{a}_{1}\left(h_{\mathbf{t}+1}\right)\right]+1 \\
& =\left[\left(\mathbf{a}_{2}\left(h_{\mathbf{t}-2}\right)+a_{2, \mathbf{t}}+a_{2, \mathbf{t}+2}\right)-\left(\mathbf{a}_{1}\left(h_{\mathbf{t}-1}\right)+a_{1, \mathbf{t}+1}\right)\right]+1 \\
& =a_{2, \mathbf{t}}+a_{2, \mathbf{t}+2}-a_{1, \mathbf{t}+1}+\left[\mathbf{a}_{2}\left(h_{\mathbf{t}-2}\right)-\mathbf{a}_{1}\left(h_{\mathbf{t}-1}\right)+1\right]
\end{aligned}
$$


But if $L_{1, \tau}\left(h_{\tau-1}\right)>L_{1, \tau}^{*}\left(h_{\tau-1}\right)$ for any $\tau \in[1+2 \mathbb{Z}]-\{\mathbf{t}+1\}$ then, $\mathbf{a}_{2}\left(h_{\mathbf{t}-2}\right)+1-\mathbf{a}_{1}\left(h_{\mathbf{t}-1}\right)=0 \Leftrightarrow \mathbf{a}_{2}\left(h_{\mathbf{t}-2}\right)+1=\mathbf{a}_{1}\left(h_{\mathbf{t}-1}\right)$ by the Lemma A. Hence,

$a_{1, \mathbf{t}+3}=a_{2, \mathbf{t}}+a_{2, \mathbf{t}+2}-a_{1, \mathbf{t}+1}$

On the other hand, we know that party 1 in stage $\mathbf{t}+1$ does not follow its strategy $\mathcal{L}_{1}^{*}$; however, from stage $\mathbf{t}+3$ to stage $\mathbf{t}-1$ it follows its decision rule $\mathcal{L}_{1}^{*}$. We can say that the total quantity of votes purchased $\mathbf{a}_{1}\left(h_{\mathbf{t}-1}\right)-\mathbf{a}_{1}\left(h_{\mathbf{t}+3}\right)$ from stage $\mathbf{t}+5$ to $\mathbf{t}-1$ is equal to $\mathbf{a}_{2}\left(h_{\mathbf{t}-2}\right)-\mathbf{a}_{2}\left(h_{\mathbf{t}+2}\right)$ if $L_{1, \tau}\left(h_{\tau-1}\right)=a_{2, \tau-1}$ for all $\tau \in[1+2 \mathbb{Z}]-\{\mathbf{t}+1, \mathbf{t}+3\}$, i.e., if

$\mathbf{a}_{1}\left(h_{\mathbf{t}-1}\right)-\mathbf{a}_{1}\left(h_{\mathbf{t}+3}\right)=a_{1, \mathbf{t}+5}+\ldots+a_{1, t-3}+a_{1, t-1}$

$\mathbf{a}_{2}\left(h_{\mathbf{t}-2}\right)-\mathbf{a}_{2}\left(h_{\mathbf{t}+2}\right)=a_{2, \mathbf{t}+4}+\ldots+a_{2, t-4}+a_{2, t-2}$

and $a_{1, \mathbf{t}+5}=a_{2, \mathbf{t}+4}, \ldots, a_{1, t-3}=a_{2, t-4}, a_{1, t-1}=a_{2, t-2}$, then,

$\mathbf{a}_{1}\left(h_{t-1}\right)-\mathbf{a}_{1}\left(h_{\mathbf{t}+3}\right)=\mathbf{a}_{2}\left(h_{t-2}\right)-\mathbf{a}_{2}\left(h_{\mathbf{t}+2}\right)$

In consequence, if we replace (B8) and (B9) in (B7) then we have that

$$
\begin{aligned}
\mathbf{a}_{1, t-1} & =\mathbf{a}_{1}\left(h_{\mathbf{t}-1}\right)+a_{1, \mathbf{t}+1}+a_{1, \mathbf{t}+3}+\left[\mathbf{a}_{1}\left(h_{t+1}\right)-\mathbf{a}_{1}\left(h_{\mathbf{t}+3}\right)\right] \\
& =\left[1+\mathbf{a}_{2}\left(h_{\mathbf{t}-2}\right)\right]+a_{1, \mathbf{t}+1}+\left[a_{2, \mathbf{t}}+a_{2, \mathbf{t}+2}-a_{1, \mathbf{t}+1}+\left[\mathbf{a}_{2}\left(h_{t-2}\right)-\mathbf{a}_{2}\left(h_{\mathbf{t}+2}\right)\right]\right.
\end{aligned}
$$

Hence,

$\mathbf{a}_{1, t-1}=1+\mathbf{a}_{2}\left(h_{\mathbf{t}-2}\right)+\left[\mathbf{a}_{2}\left(h_{\mathbf{t}-2}\right)+a_{2, \mathbf{t}}+a_{2, \mathbf{t}+2}-\mathbf{a}_{2}\left(h_{\mathbf{t}+2}\right)\right]$

But

$\mathbf{a}_{2}\left(h_{\mathbf{t}+2}\right)=\mathbf{a}_{2}\left(h_{\mathbf{t}-2}\right)+a_{2, \mathbf{t}}+a_{2, \mathbf{t}+2}$

Thus, if we replace (B11) in (B10) we have that

$\mathbf{a}_{1, t-1}=1+\mathbf{a}_{2}\left(h_{\mathbf{t}-2}\right)$

On the other hand, if $h_{s}=\left\langle\mathcal{L}_{i}^{*}, \mathcal{L}_{2}\right\rangle$ then,

$$
\begin{aligned}
L_{1, \tau}^{*}\left(h_{\tau-1}^{*}\right) & =\left[\mathbf{a}_{2}\left(h_{\tau-1}\right)-\mathbf{a}_{1}\left(h_{\tau-2}\right)\right]+1 \\
& =\left[\left(\mathbf{a}_{2}\left(h_{\tau-3}\right)+a_{2, \tau-1}\right)-\left(\mathbf{a}_{1}\left(h_{\tau-4}\right)+a_{1, \tau-2}\right)\right]+1 \\
& =\left[\mathbf{a}_{2}\left(h_{\tau-3}\right)-\mathbf{a}_{1}\left(h_{\tau-4}\right)\right]+1+a_{2, \tau-1}-a_{1, \tau-2} \\
& =L_{1, \tau-2}^{*}\left(h_{\tau-3}^{*}\right)+a_{2, \tau-1}-a_{1, \tau-2} \\
& =a_{1, \tau-2}+a_{2, \tau-1}-a_{1, \tau-2} \\
& =a_{2, \tau-1}
\end{aligned}
$$


for any $\tau \in 1+2 \mathbb{Z}_{+}$. Hence,

$\mathbf{a}_{1}\left(h_{s-1}\right)=1+\mathbf{a}_{2}\left(h_{s-2}\right)$

Let us use (B12) and (B13) to prove that $\mathbf{a}_{2}\left(h_{t}\right)=\mathbf{a}_{2}\left(h_{s}\right)$. Note that

$\mathbf{e}_{2}\left(\mathbf{a}_{2}\left(h_{t}\right)\right) \leq B^{2}<\mathbf{e}_{2}\left(1+\mathbf{a}_{2}\left(h_{t}\right)\right)$

by definition of $h_{t}$ and

$\mathbf{e}_{2}\left(\mathbf{a}_{2}\left(h_{s}\right)\right) \leq B^{2}<\mathbf{e}_{2}\left(1+\mathbf{a}_{2}\left(h_{s}\right)\right)$

by definition of $h_{s}$. Hence, it is sufficient to prove that $\mathbf{e}_{2}\left(\mathbf{a}_{2}\left(h_{t}\right)\right)=\mathbf{e}_{2}\left(\mathbf{a}_{2}\left(h_{s}\right)\right)$ given that $\mathbf{e}_{2}$ is a 1-1 function. Seeking a contradiction, suppose that $\mathbf{e}_{2}\left(\mathbf{a}_{2}\left(h_{t}\right)\right)>\mathbf{e}_{2}\left(\mathbf{a}_{2}\left(h_{s}\right)\right)$. Therefore, given inequality (B14), we have that

$B^{2} \geq \mathbf{e}_{2}\left(\mathbf{a}_{2}\left(h_{t}\right)\right) \geq \mathbf{e}_{2}\left(1+\mathbf{a}_{2}\left(h_{s}\right)\right)>B^{2}$

which is a contradiction. If we assume that $\mathbf{e}_{2}\left(\mathbf{a}_{2}\left(h_{s}\right)\right)>\mathbf{e}_{2}\left(\mathbf{a}_{2}\left(h_{t}\right)\right)$ then, given inequality (B15), it holds that

$B^{2} \geq \mathbf{e}_{2}\left(\mathbf{a}_{2}\left(h_{s}\right)\right) \geq \mathbf{e}_{2}\left(1+\mathbf{a}_{2}\left(h_{t}\right)\right)>B^{2}$

which is a contradiction. Hence, by (B16) and (B17) we have that $\mathbf{e}_{2}\left(\mathbf{a}_{2}\left(h_{t}\right)\right)=\mathbf{e}_{2}\left(\mathbf{a}_{2}\left(h_{s}\right)\right)$. Therefore, $\mathbf{a}_{2}\left(h_{t}\right)=\mathbf{a}_{2}\left(h_{s}\right)$ given that $\mathbf{e}_{2}$ is a 1-1 function. In consequence, if

$$
\begin{aligned}
\mathbf{a}_{2}\left(h_{t}\right)=\mathbf{a}_{2}\left(h_{s}\right) & \Leftrightarrow \mathbf{a}_{2}\left(h_{t-2}\right)+a_{2, t}=\mathbf{a}_{2}\left(h_{s-2}\right)+a_{2, s} \\
& \Leftrightarrow \mathbf{a}_{2}\left(h_{t-2}\right)+0=\mathbf{a}_{2}\left(h_{s-2}\right)+0 \\
& \Leftrightarrow \mathbf{a}_{2}\left(h_{t-2}\right)=\mathbf{a}_{2}\left(h_{s-2}\right)
\end{aligned}
$$

then $\mathbf{a}_{1}\left(h_{t-1}\right)=\mathbf{a}_{1}\left(h_{s-1}\right)$ by (B11) and (B12). Hence, $\mathbf{e}_{1}\left(\mathbf{a}_{1}\left(h_{t-1}\right)\right)$ $=\mathbf{e}_{1}\left(\mathbf{a}_{1}\left(h_{s-1}\right)\right)$ given that $\mathbf{e}_{1}$ is a function. In consequence, we have demonstrated the following equality $W-\mathbf{e}_{1}\left(\mathbf{a}_{1}\left(h_{t-1}\right)\right)=W-\mathbf{e}_{1}\left(\mathbf{a}_{1}\left(h_{s-1}\right)\right)$, i.e., $v_{1}\left(h_{t}\right)=v_{1}\left(h_{s}\right)$.

Case 2. $B^{2}>>B^{1}$. Let us prove that if $B^{2}>>B^{1}$ then $v_{1}\left(h_{s}\right)=v\left(h_{t}\right)$ for any $h_{t}=\left\langle\mathcal{L}_{1}, \mathcal{L}_{2}\right\rangle$ such that $h_{s}=\left\langle\mathcal{L}_{1}^{*}, \mathcal{L}_{2}\right\rangle$ and $\mathcal{L}_{1}^{*} \neq \mathcal{L}_{1}$. In effect, if $B^{2}>>B^{1}$ then $\left|h_{s}\right|=\left|h_{t}\right| \in 1+2 \mathbb{Z}_{+}$; and hence, $a_{1, t}=a_{1, s}=0$ by definition of $h_{t}$ and $h_{s}$. On the other hand, it holds that

$\mathbf{e}_{1}\left(\mathbf{a}_{1}\left(h_{s}\right)\right) \leq B^{1}<\mathbf{e}_{1}\left(1+\mathbf{a}_{1}\left(h_{s}\right)\right)$

by definition of $h_{s}$ and

$\mathbf{e}_{1}\left(\mathbf{a}_{1}\left(h_{t}\right)\right) \leq B^{1}<\mathbf{e}_{1}\left(1+\mathbf{a}_{1}\left(h_{t}\right)\right)$ 
by definition of $h_{t}$. Its verify that $\mathbf{e}_{1}\left(\mathbf{a}_{1}\left(h_{s}\right)\right)=\mathbf{e}_{1}\left(\mathbf{a}_{1}\left(h_{t}\right)\right)$. In effect, we reason by contradiction. Let us assume that

$\mathbf{e}_{1}\left(\mathbf{a}_{1}\left(h_{t}\right)\right)>\mathbf{e}_{1}\left(\mathbf{a}_{1}\left(h_{s}\right)\right)$

Therefore, $B^{1}>B^{1}$ by inequalities (B18) and (B19), which is a contradiction. If we assume that

$\mathbf{e}_{1}\left(\mathbf{a}_{1}\left(h_{s}\right)\right)>\mathbf{e}_{1}\left(\mathbf{a}_{1}\left(h_{t}\right)\right)$

then $B^{1}>B^{1}$ by (B18) and (B19), which is a contradiction. Hence, if (B20) and (B21) lead to a contradiction then $\mathbf{e}_{1}\left(\mathbf{a}_{1}\left(h_{s}\right)\right)>\mathbf{e}_{1}\left(\mathbf{a}_{1}\left(h_{t}\right)\right)$ holds. Thus, $\mathbf{a}_{1}\left(h_{t}\right)=\mathbf{a}_{1}\left(h_{s}\right)$ by definition of $\mathbf{e}_{1}$. In consequence, $v_{1}\left(h_{t}\right)=v_{1}\left(h_{s}\right)=$ $-\mathbf{e}_{1}\left(\mathbf{a}_{1}\left(h_{t}\right)\right)$. Therefore, by cases 1 and $2, v_{1}\left(h_{s}\right) \geq v_{1}\left(h_{t}\right)$ holds for any $h_{t}=\left\langle\mathcal{L}_{1}, \mathcal{L}_{2}\right\rangle$ such that $h_{s}=\left\langle\mathcal{L}_{1}^{*}, \mathcal{L}_{2}\right\rangle$ and $\mathcal{L}_{1}^{*} \neq \mathcal{L}_{1}$ for any $\mathcal{L}_{2}$. 